\title{
Adverse Wear in MOM Hip-Arthroplasty Related to the Production of Metal Fragments at Impingement Sites
}

\author{
T. K. Donaldson', E. J. Smith ${ }^{2}$, A. Koutalos ${ }^{3}$, A. John', J. Y. Lazennec ${ }^{5}$, I. C. Clarke ${ }^{*}$ \\ ${ }^{1}$ Empire Orthopedics, Colton, CA, USA \\ ${ }^{2}$ Department of Orthopaedics, University of Bristol, Bristol, England \\ ${ }^{3}$ Department of Orthopaedics, University Hospital of Larissa, Larissa, Greece \\ ${ }^{4}$ Department of Orthopaedics, University of Cardiff and Vale NHS Trust, Wales, England \\ ${ }^{5}$ Department of Orthopedic and Trauma Surgery, La Pitié-Salpêtrière Hospital, University of Paris, Paris, France \\ ${ }^{6}$ Department of Orthopaedics, Loma Linda University Medical Center, Loma Linda, CA, USA \\ Email: thomas.donaldson100@gmail.com, evert@evertsmith.com, akoutmed@gmail.com, alunjohn@me.com, \\ lazennec.jy@wanadoo.fr, ^ithipgeek15@yahoo.com, ian.clarke@llu.edu
}

How to cite this paper: Donaldson, T.K., Smith, E.J., Koutalos, A., John, A., Lazennec, J.Y. and Clarke, I.C. (2018) Adverse Wear in MOM Hip-Arthroplasty Related to the Production of Metal Fragments at Impingement Sites. Open Journal of Orthopedics, 8, 381-412.

https://doi.org/10.4236/ojo.2018.810041

Received: June 2, 2018

Accepted: October 13, 2018

Published: October 16, 2018

Copyright (c) 2018 by authors and Scientific Research Publishing Inc. This work is licensed under the Creative Commons Attribution International License (CC BY 4.0).

http://creativecommons.org/licenses/by/4.0/

\begin{abstract}
Metal on metal (MOM) bearings were reintroduced as resurfacing arthroplasty (RA) for the younger, more active patient and were later incorporated into total hip arthroplasty (THA). Early results were encouraging. However, recent publications identified adverse tissue responses to metal debris, such that the majority of MOM designs have been abandoned due to the increase in cobalt-chromium ( $\mathrm{CoCr}$ ) debris and associated metal ions. Reports of MOM THA cited risks that included acetabular cups with high-inclination angles, i.e. "edge-loading", and "trunnionosis". Hip impingement was also a cited risk in one MOM study, with "type-IV" wear noted to be a sliding/impaction type of wear, characterized by deep scratches. Sliding/impaction wear mechanisms produced at impingement are not well represented in current MOM literature. Therefore, our objective in this review was to consolidate evidence for impingement risks. We hypothesize that hip impingement and subluxation with metal-backed acetabular cups can trigger wear mechanisms that result in, 1) femoral-neck notching, 2) release of large metal particles, 3) production of uniquely large scratches, defined as "microgrooves" on heads and cups, 4) formation of "polar" and "basal" microgrooves precisely aligning with cup profiles during impingement, and 5) equatorial microgrooves relate to soft-tissue sites of impingement. Relevant risk scenarios were evaluated and included hip impingement in both sitting and standing postures, head subluxation, wear patterns defining in-vivo component positions, and evidence for circulating metal fragments. The study relied on map-
\end{abstract}


ping of wear patterns to deduce in-vivo positioning of devices and relied on surrogate femoral stems of the same brand to simulate neck-cup impingement. EOS imaging techniques were used to analyze functional-sitting and functional-standing postures and prove existence of hip impingement sites in patients. The study identified 8-risk scenarios for wear damage on MOM bearings. The microgrooves on femoral-heads crossing the main-wear area (polar) and non-wear regions (basal) aligned well with cup-rim profiles at impingement sites. This may represent the first description of such large scratches (40 - $300 \mu \mathrm{m}$ wide) we termed microgrooves, that formed on femoral heads at sites representative of prosthetic impingement. As an abrasive wear process, similar to the formation of femoral-neck notches, these would have been acquired over millions of gait cycles. The pitting and linear microgrooves crossing the non-wear areas of heads (basal) represented the ingress sites of circulating metal particles. Similar microgrooves were evident in acetabular cups, also signifying $3^{\text {rd }}$-body abrasion by large metal particles. Hip impingement and head subluxation were implicated by the unequivocal evidence of $3^{\text {rd }}$-body abrasive wear as the triggering events producing large metal fragments. One caveat regarding retrieval studies is that such damage may be only representative of failed MOM devices. This study demonstrated that emerging technologies such as $\operatorname{EOS}^{\mathrm{TM}} \mathrm{x}$-ray analyses can reveal subtle changes in implant positioning using patient shifts in functional postures (sitting, standing, hyper-extension, etc.), and thereby assess impingement/subluxation risks in the clinical setting before failure occurs.

\section{Keywords}

Resurfacing Arthroplasty, MOM

\section{Introduction}

Large-diameter metal-on-metal (MOM) bearings were re-introduced as hip resurfacing arthroplasty (RA) concepts [1] [2] with the expectation that fluid-film lubrication regimes would be particularly beneficial in minimizing wear [1] [3]-[10]. Following a small but worrisome incidence of femoral-neck fractures [11] [12] [13] [14] [15] is a large diameter, MOM bearings were also incorporated into total hip arthroplasty (THA) intended for younger and more active patients. Early MOM studies appeared encouraging [1] [2] [14] [16] [17] [18] and related simulator studies demonstrated acceptable wear performance using 40 - 60 mm diameter MOM [19] [20] [21] [22] [23]. Unfortunately, initially good results with RA and THA were not maintained and the majority of MOM designs have now been abandoned due to excessive cobalt-chromium release (CoCr) debris and associated metal ions [24]-[33]. Commonly cited risks include cups positioned with higher inclination angles ("steep cups") and taper corrosion with modular femoral heads ("trunnionosis"). Clinical and retrieval evidence has attributed adverse wear to "edge-loading" of acetabular cups, be- 
lieved due to a combination of excessive lateral-inclination, and/or excessive anteversion [27] [29] [34] [35]. A $2^{\text {nd }}$ commonly cited risk in THA retrievals has been corrosion between the modular femoral head and its femoral taper [36] [37]. Possibly, the use of $36-60 \mathrm{~mm}$ diameter heads adversely influenced the underlying corrosion dynamics [38].

Hip impingement was also cited as a common risk with McKee-Farrar type THA [39] [40] [41]. Howie et al. (2005) were able to determine component positioning in-vivo because the femoral stems were of monobloc design. They noted that cup-to-neck impingement sites demonstrated fatigue damage from sub-surface fractures, resulting in extrusion of large metal fragments. This was believed to represent a sliding/impaction type of wear mechanism. Such femoral-neck/stem impingement with acetabular cups was not surprising because the THA literature is replete with documentation of dislocations, liner impingements, rim fractures, ceramic chipping, neck notching, component disassociation and related black-staining of ceramic bearings [42]-[48]. Prevalence of THA impingement in retrieval studies has varied from $39 \%$ to $83 \%$ of cases [49] [50] [51] [52] [53]. The McKee-Farrar study also provided microscopic details of CoCr wear patterns. Four types were described; Type I-II wear patterns contained a background of randomly-oriented, fine scratches, with $\mathrm{CoCr}$ surfaces retaining their original reflective appearance. We would also note as typical strings of exposed carbides 5 - $10 \mu \mathrm{min}$ size (Figure 1). Type III wear patterns had randomly-oriented scratches with a higher roughness that resulted in loss of reflective surface (Figure 1(B)). In contrast, type IV wear was characterized by deep, parallel scratches that created a 10 -fold higher roughness due to scratches typically $40-100 \mu \mathrm{m}$ wide with linearly-striated side-walls (Figure $1(\mathrm{C})$ ). We depict here SEM observations of a deep scratch from Howie et al. (Figure 1(D)). Using white-light interferometry (WLI) we confirmed the presence of dramatically long scratches typically $100 \mu \mathrm{m}$ wide and 2 - $4 \mu \mathrm{m}$ deep (Figure 2) [40] [54] [55]. These we termed "microgrooves" (Figure $1(\mathrm{C})$ ) to uniquely distinguish them from the fine, background scratches on CoCr surfaces (Figure 1(A), Figure 1 (B)) and the "stripe wear" defects reported in ceramic retrievals [51] [56] [57].

In our THA study [54], pitting and microgrooves were detectable on all retrieved components (Figure 1), being more than 10-fold larger than typical background $\mathrm{CoCr}$ scratches and carbides. Microgrooves were identifiable by extreme lengths, raised lips and ranging $40-160 \mu \mathrm{m}$ with conspicuous longitudinal striations (Figure 1(C), Figure 2). These appeared very similar to type-IV scratches reported in the McKee-Farrar study (Figure 1(D)) [40]. Our assumption was that $100 \mu \mathrm{m}$ wide scratches had been created by CoCr particles $100 \mu \mathrm{m}$ or larger. However, we found no evidence to support the presence of large $\mathrm{CoCr}$ fragments. It is therefore significant that $96 \%$ of particles found embedded in the plastic liners of metal-on-polyethylene (MPE) retrievals were metallic, averaging $126 \mu \mathrm{m}$ in size (ECD: equivalent circle diameter), and some even larger than 2.5 

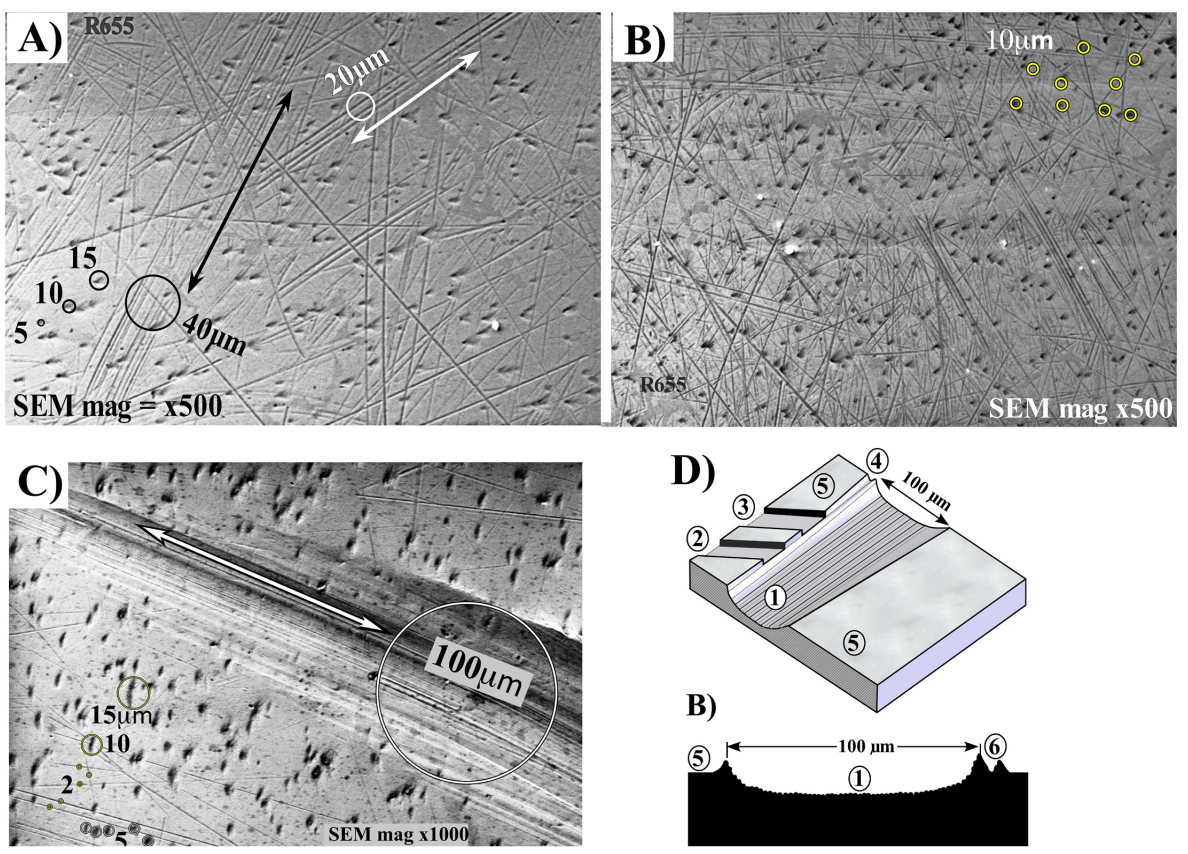

Figure 1. SEM image of Cor scratches and carbide inclusions (46 mm BHR head): (A) Type I-II wear, 5 - $15 \mu \mathrm{m}$ scale markers indicate fine scratches, carbides and $20-40 \mu \mathrm{m}$ parallel scratch formation: (B) Type-III wear, $10 \mu \mathrm{m}$ scale markers; (C) Type-IV wear, "microgroove" with striations (100 $\mu \mathrm{m}$ scale marker); (D) Type-IV scratch modeled on SEM image showing small scratches (\#2-4) on CoCr surface (5) intersecting $100 \mu \mathrm{m}$ microgroove (as in Howie et al., Figure 5) [40].

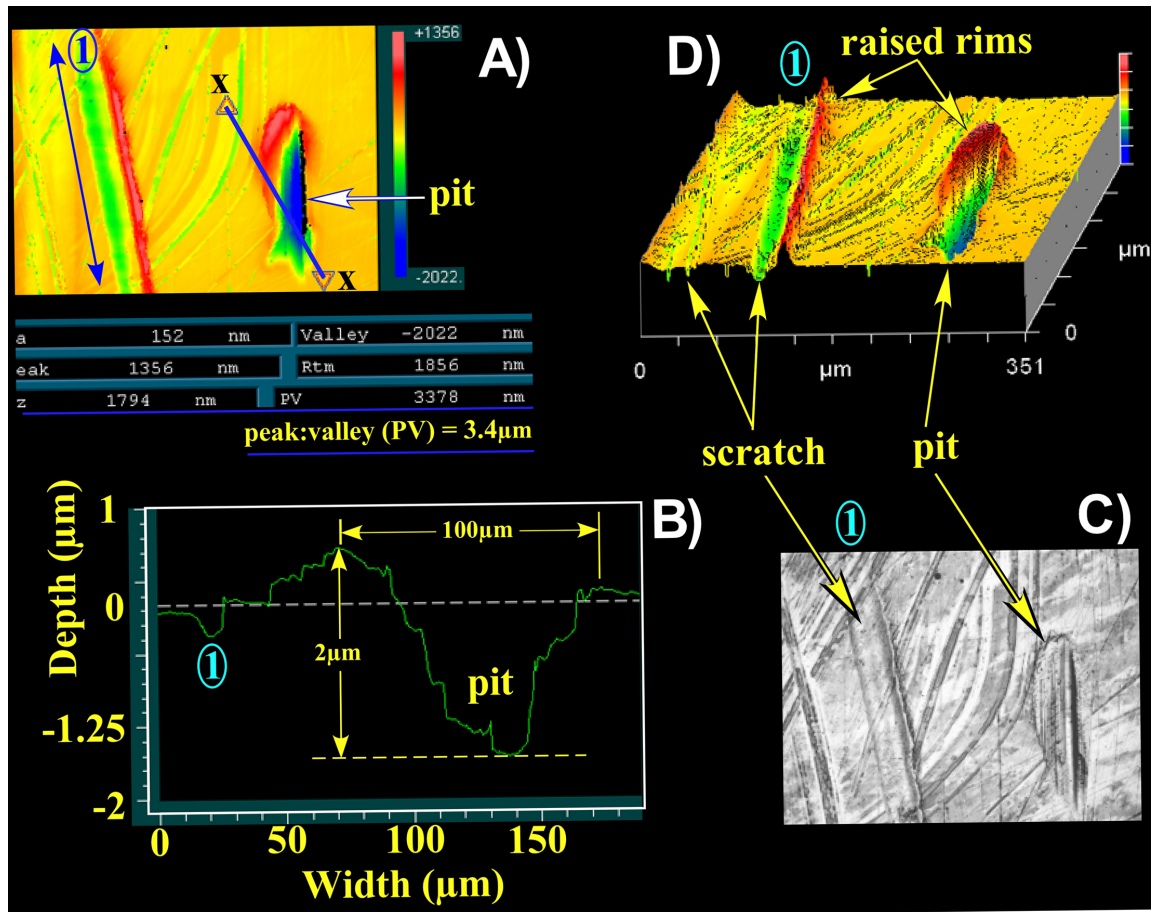

Figure 2. White light interferometer (WLI) images: fine scratches adjacent to large pit: (A) View of scratch (1) and profile trace ( $\mathrm{xx}$ ) crossing pit; (B) Cross-section of pit ( $\mathrm{xx}$ ) as traced in image-A; (C) Light-microscopy image (in image-A); (D) 3D-oblique view: raised lips around scratch and pit. 
$\mathrm{mm}$ [46] [58]. The conceptual sliding/impaction/fatigue wear mechanisms that were described relative to THA impingement [40] are not represented in current literature espousing the risks of "steep-cups" and "trunnion corrosion". Therefore, the objective of this study was to consolidate the available evidence for impingement/wear mechanisms, and to determine from this assemblage of information (Table 1), was this could be a clinically relevant risk scenario, or should it be rejected.

We formulated the following hypothesizes:

1) THA impingement can readily occur in either sitting or standing postures.

2) Neck notching is an impingement/abrasion process produced by the cup-rim over millions of cyclic hip motions.

3) Hip impingement and femoral-head subluxation release metal fragments into the joint space.

4) Ingress of metal particles into MOM bearings produces $3^{\text {rd }}$-body wear damage most evident in "non-wear" (basal) regions of femoral heads.

5) Cups positioned on basal and polar scratches ("microgrooves") on femoral heads relate to sites of "simulated" prosthetic impingement.

6) Cups positioned along equatorial microgrooves do not represent sites of 'simulated' prosthetic impingement.

7) Head microgrooves are produced by abrasion over millions of cyclic hip motions due to a combination of, a) cup-rim cycling across head surface (2-body wear), and b) motion of entrapped metal particles ( $3^{\text {rd }}$-body wear).

8) Cup microgrooves represent $3^{\text {rd }}$-body wear by entrapped metal particles.

\section{Hip Subluxation in Functional Standing and Sitting Postures}

It is known that cup positions change depending on patient position (Figure 3). During sitting, the pelvis generally tilts posteriorly and both cup anteversion and inclination increase (Figure 4). Assessment of patient's lateral or supine position during surgery does not eliminate the risk of impingement and subluxation,

Table 1. Evidence modules comparing impingement and wear damage in total hip arthroplasty (THA) and resurfacing arthroplasty (RA) [40] [54] [55].

\begin{tabular}{cccc}
\hline$\# \#$ & Assemblage of MOM Wear Evidence & THA & RA \\
\hline 1 & Hip subluxation in functional standing and sitting postures & yes & yes \\
2 & Wear patterns defining in-vivo component positions & yes & yes \\
3 & Notching mechanism in femoral necks & yes & - \\
4 & Pits, microgrooves and plastically-deformed gouges & yes & yes \\
5 & Cup positions defining femoral-neck impingements & yes & yes \\
6 & Evidence of metal debris circulating in the hip joint & yes & yes \\
7 & Demonstrating spino-pelvic/hip motions at impingement & yes & yes \\
8 & Discussion of MOM wear mechanisms & & \\
\hline
\end{tabular}



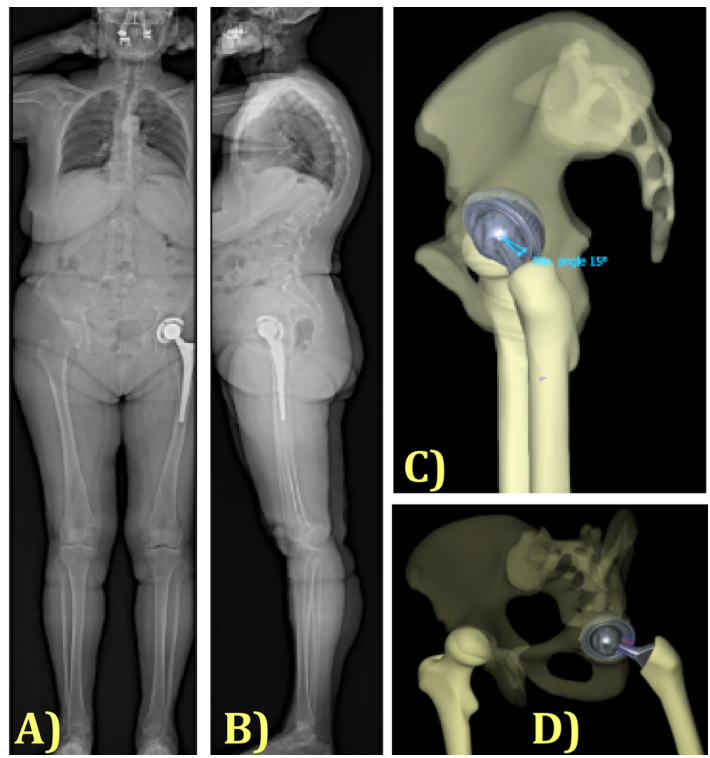

Figure 3. Standing EOS-radiographs with 3D-reconstructions showing $28 \mathrm{~mm}$ THA with anterior subluxation (left-hip, female patient): (A) EOS anterior view; (B) EOS lateral view; (C) femoral-neck on cup rim in lateral view; (D) Oblique view of femoral-neck impinging cup rim.
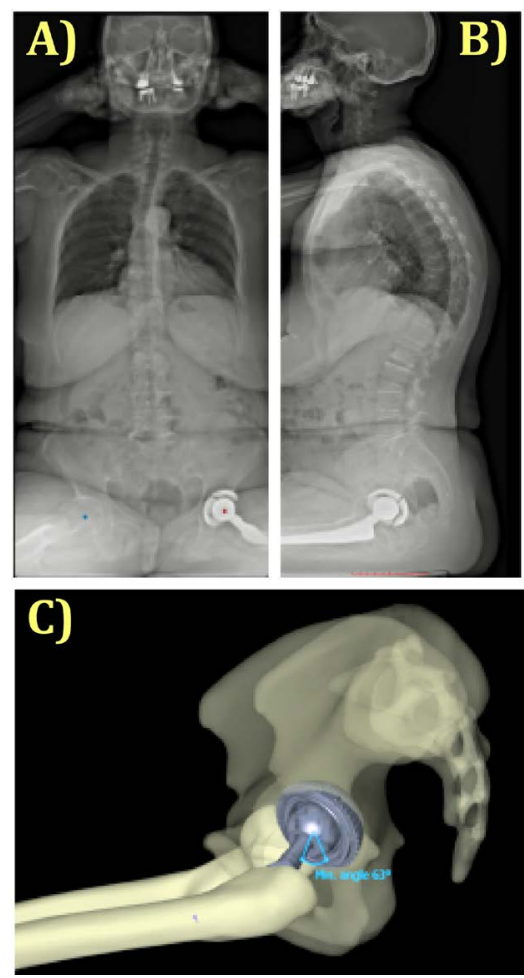

Figure 4. Sitting EOS-radiographs: (A) anterior view; (B) lateral view; (C) lateral view of 3D-reconstruction, no limitation to hip motion.

even if cup position is representative of the so-called "safe zone" [59]. The high rate of THA impingement [15] [22] [31] [45] [49] together with the fact that dislocation can occur when the cup is placed in the "safe zone" has demonstrat- 
ed that hip impingement, subluxation and even dislocation can occur due to functional postural changes. The trial reduction intraoperatively cannot determine impingement risks in the patient's various functional postures. Moreover, the spino-pelvic mobility of each patient makes the functional position of the cup complex. [60] Patients with pelvic stiffness have less change in anteversion and inclination with sitting, i.e. the cup should be implanted in more inclination/anteversion to improve motion. The opposite is true in patients with a hypermobile pelvis, usually women. The cup needs to be placed in less inclination/anteversion because with sitting there will be larger than normal shifts in cup inclination/anteversion while risk of impingement or even dislocation increases [61]. In addition, the balance of the spine in the sagittal plane requires attention. Patients with unbalanced spines should 1) have sagittal deformity corrected before proceeding to THA, or 2) have cup placed in less anteversion because of the risk of posterior impingement with a retroverted pelvis and increased acetabular anteversion [62].

\section{Wear Patterns Defining In-Vivo Component Positions}

The key measure in retrieval analyses lies in discerning the in-vivo orientation of components. The prior study of McKee-Farrar THA had the advantage that the femoral components represented a monoblock design [40]. To determine in-vivo positioning of modular bearings, we utilized wear-pattern mapping developed from simulator studies [21] [63] [64]. This unique approach defined component wear-patterns using a combination of light microscopy, white light interferometry (WLI: NewView-600, ZygoInc, Tucson, AZ), and scanning electron microscopy (SEM: MA-15: Zeiss Inc., New York). Wear patterns on the retrieved components were stained red to illustrate main-wear zones for photography (Figure 5: MWZ, area of habitual wear) and also to delineate non-wear zones (Figure 5 NWZ: region of incidental, non-wear) [54]. This was necessary for photography because the retrieved $\mathrm{CoCr}$ bearings retained their original, highly-reflective appearance. In addition, cup surfaces had to be taped to eliminate multiple images reflected from convex surfaces (see Figure 24) [21] [54].

Femoral heads were photographed in four orthogonal views and one polar view whereas cups were simply photographed en-face. Positioning of the narrow NWZ-margin (Figure 5(A), B: S) defined the superior aspect of the femoral head and position of the habitual wear area (MWZ) in vivo. This we validated on THA received with heads fused to their femoral trunnions (Figure 6). To define the cup's in-vivo position, the typically eccentric position of its MWZ area was matched to that of the femoral MWZ. The sites of microgrooves visible to the naked eye on head and cup components were colored for photography (Figure 5, Figure 6: polar as blue, equatorial as green, basal as black).

\section{Notching Mechanism in Femoral Necks}

Howie et al. [40] noted that "femoral-neck on cup rim" impingement resulted in a fatigue-wear mechanism capable of releasing large $\mathrm{CoCr}$ particles. While the 


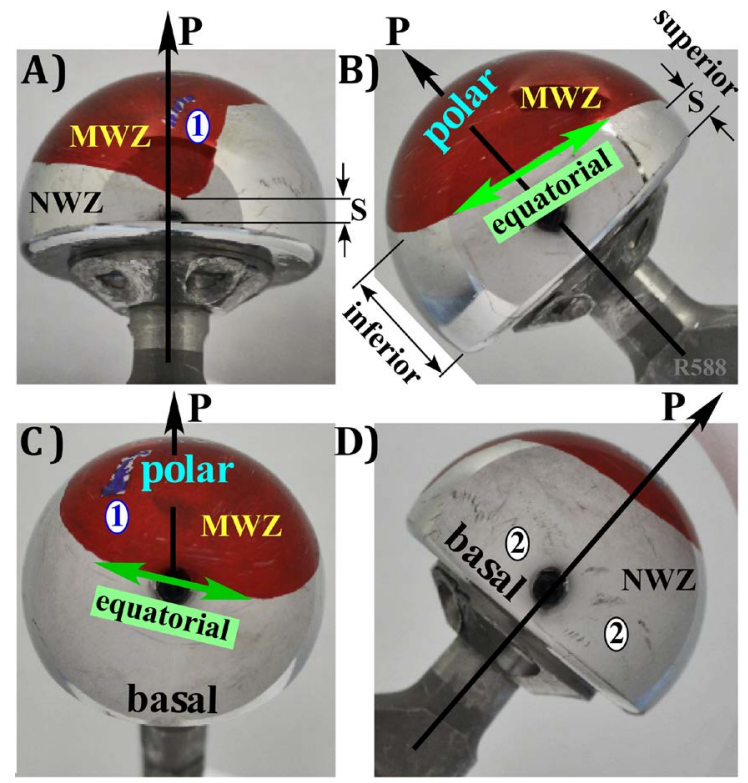

Figure 5. Main-wear zone (MWZ) on THA retrieval with head fused to trunnion (left hip, $50 \mathrm{~mm}$ Magnum THA) [65]. (A) View-1 superior region: narrow non-wear zone (S) and polar microgroove (1); (B) View-2 anterior: equatorial and polar landmarks; (C) View-3: basal, equatorial, and polar site with microgroove (1); (D) View-4 posterior: basal microgrooves.

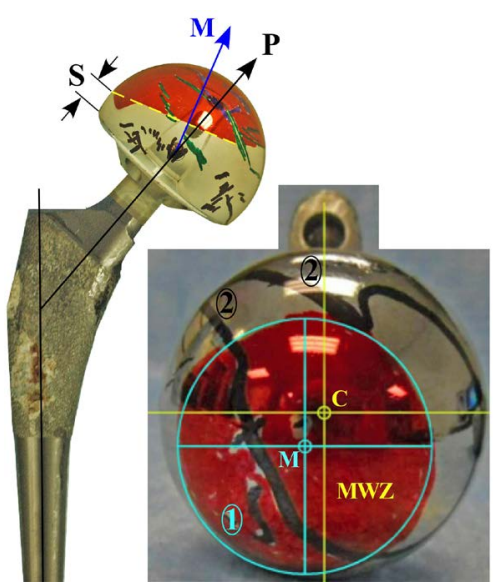

Figure 6. Wear pattern on fused-head (50 mm Magnum THA) illustrating position of NWZ narrow region (S) [65]. Inset shows polar axis (P), MWZ centroidal axis (M) and microgrooves, polar (1) and basal (2). MWZ area $2200 \mathrm{~mm}^{2}$ represented $56 \%$ of hemispherical area (50 $\mathrm{mm}$ MOM).

authors did not share impingement evidence in this McKee-Farrar study, there are ample reports of femoral-neck notching and related risks [42] [43] [44] [48] [66]-[71]. There was no opportunity to check for circumferential neck-markings indicative of cup impingement because the majority of our MOM bearings were retrieved without mating femoral stems (Figures 7-9). While some cases could be related to multiple dislocations [66]. the anatomy of these notches indicated an abrasive and/or fatigue-wear phenomena that occurred repetitively over millions of impingements (Figure 7). For example, the titanium femoral neck in 

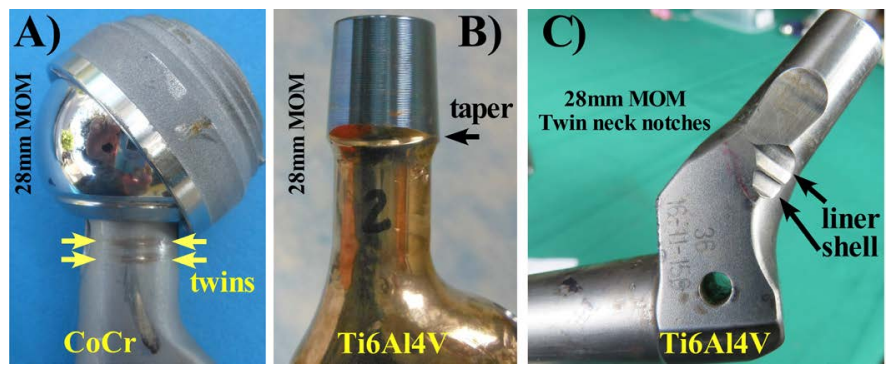

Figure 7. Cup rim impingement indicated by circumferential neck scratchess, (A) twin defects on CoCr neck; (B) notch on TI6Al4Vtrunnion, and (C) two notches on TI6Al4V neck.

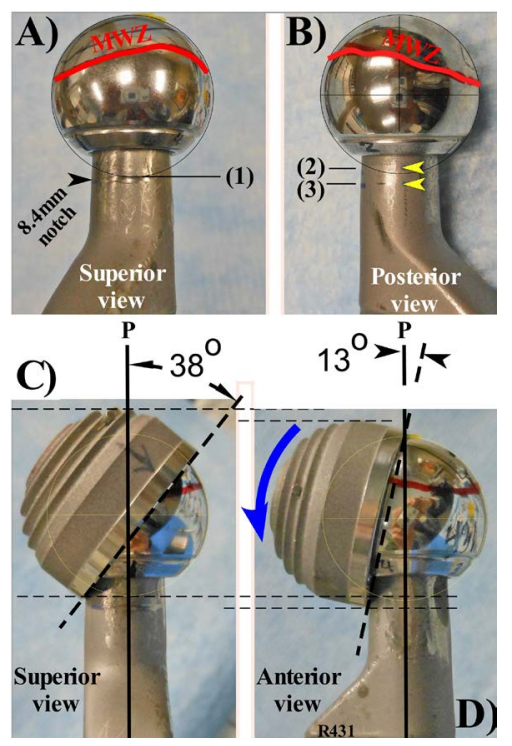

Figure 8. Impingement indicated by circumferential notches on femoral neck $(28 \mathrm{~mm}$ Metasul THA): (A) notch (1) in superior femoral neck (female gymnast, squatting exercises); (B) twin notches $(2,3)$ in posterior neck; (C) cup rim contacting notch-3, posterior neck; (D) head subluxed, rim contacting notch-1 on superior neck.

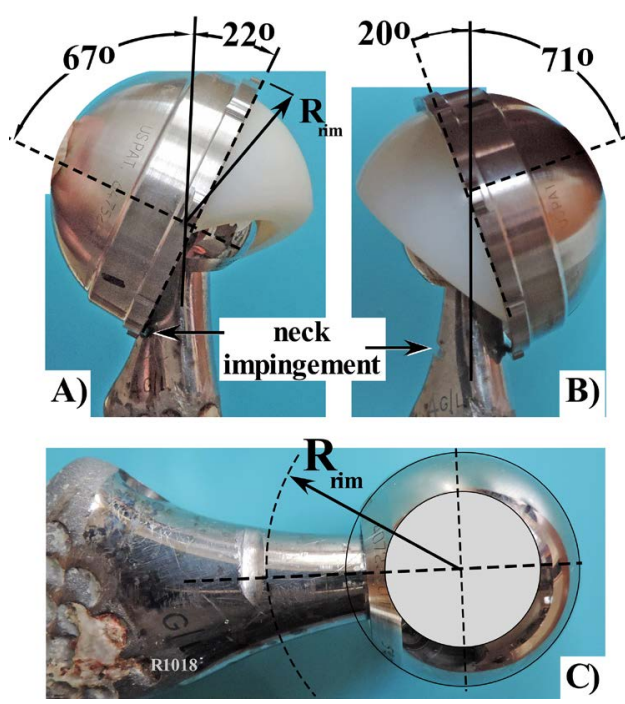

Figure 9. Metal-on-polyethylene THA with neck notch at impingement site. 
our SROM case (Figure $7(\mathrm{C})$ ) had two notches that exactly matched the rim profiles of the Pinnacle shell and CoCr liner [71]. This resembled a precision-machining process, unequivocal retrieval evidence that such neck-notching required millions of wear cycles to acquire. Some femoral necks demonstrated two and sometimes three notches (Figure 7(A)). Using geometric THA models, [43] we have shown that the proximal notch indicated the $1^{\text {st }}$ impingement site (Figure 7(A)). For the more distal notch, the femoral head had to sublux to a more vertical position, relative to the polar axis (Figure $8(B)$, Figure $8(D)$ ). Such a mechanism, whereby the femoral neck was worn by repetitive oscillations of the cup rim, we defined by the acronym "NAR-damage" (Table 2). This was variable, from cosmetic scratches more typical on $\mathrm{CoCr}$ necks (Figure $7(\mathrm{~A})$ ) to deep notches found onTi6Al4V necks (Figure 7(B), Figure 7(C)). In this regard, it is notable that the majority of mating $\mathrm{CoCr}$ cups showed no comparable rim damage.

There are many factors involved in THA impingement and certainly head: neck ratios and range of motion are important with many retrieval studies featuring $28 \mathrm{~mm}$ THA (Figure 7). Nevertheless, THA designs optimized for range of motion can also impinge and produce neck notches (Figure 9).

\section{Pits, Microgrooves and Plastically-Deformed Gouges}

There was unequivocal evidence of large pits in all retrieved MOM bearings (Figure 10(A)). The basal head areas (non-wear zone) in particular provided the most dramatic evidence. This was likely because basal regions represent the first sites of ingress for circulating metal particles [49] [58] and such damage was not mitigated by habitual wear during patient's normal activities (Figure 5, Figure 6: non-wear zone). Strings of surface pits were characterized by $100-300 \mu \mathrm{m}$ width, smooth entry points, longitudinal striations indicating direction of travel, and lips raised towards the point of egress (Figure 10(B)). WLI imaging showed that pits typically varied $3-10 \mu \mathrm{m}$ in depth (Figure 11, Figure 12). The pits presented partly as a ploughing action that raised scratch lips above the surface (plastic deformation) and partly abrasive action (releasing CoCr debris). For

Table 2. Wear damage observed on retrieved MOM bearings.

\begin{tabular}{cccccc}
\hline$\# \#$ & Acronymn & Details of Wear Mechanism & Type & THA & RSA \\
\hline 1 & NAR & Femoral neck abrasion by cup rim & Abrasion, deformation & yes & no \\
2 & 3CO & 3rd body wear by CoCr debris & Abrasion & yes & yes \\
3 & FHG & Femoral head gouges & Plastic deformation & yes & - \\
4 & 2CR & 2-body damage to head by cup rim & Abrasion, deformation & yes & yes \\
5 & 3CR & Entrapped particles (3rd body) & Abrasion & yes & yes \\
6 & 3TI & 3rd body wear by Ti6Al4V debris & Abrasion & yes & - \\
7 & TTL & Titanium contamination & Metal transfer & yes & - \\
8 & 2OR & Surgical damage & Abrasion, metal transfer & yes & - \\
\hline
\end{tabular}




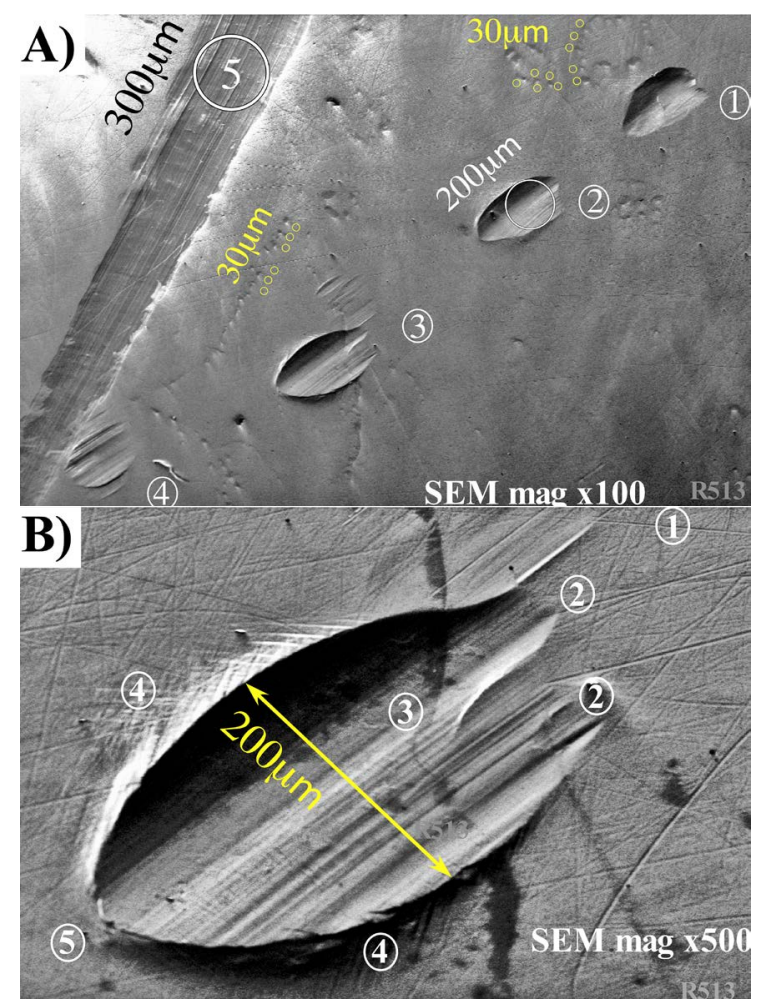

Figure 10. SEM image of string of pits in basal head (38 mm M2a): (A) $200 \mu \mathrm{m}$ pits (\#1-4) juxtaposed to $300 \mu \mathrm{m}$ microgroove (5), $30 \mu \mathrm{m}$ circles indicate carbides; (B) SEM image of pit defect, (1) fine CoCr scratches, (2) entry point of particle, (3) longitudinal striations, (4) plastic deformation in defect lips/shoulders, and (5) exit terminus.

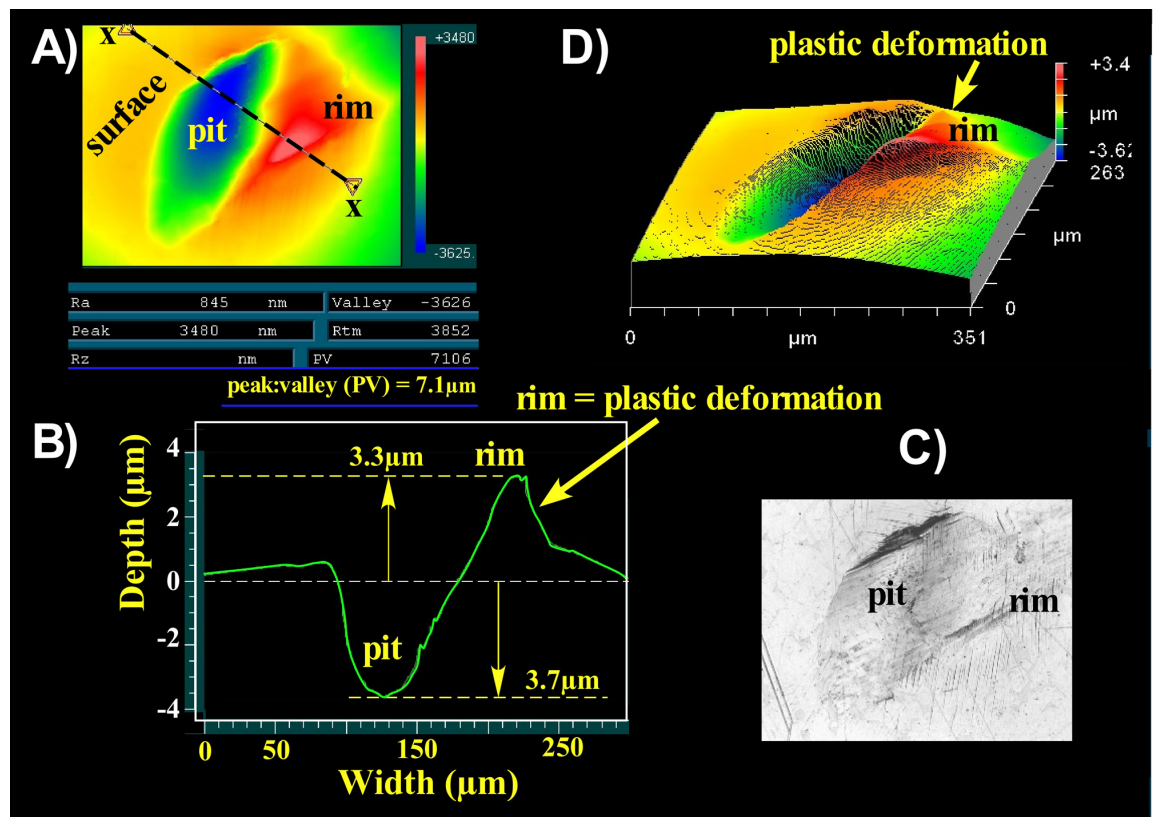

Figure 11. Imaging of pit in basal head area following repetitive sub-clinical subluxations (RSS) and 2 dislocations (complex case, 65-year old rheumatoid patient, $44 \mathrm{~mm}$ Magnum) [72] [73]. (A) profile line across pit and elevated lip; (B) Cross-sectional view 100um defect (valley 3.7 um, plastically-deformed lip $3.3 \mathrm{um}$ ); (C) Light microscopy image (in image-A); (D) WLI oblique view of plastically-deformed lip and shoulder. 


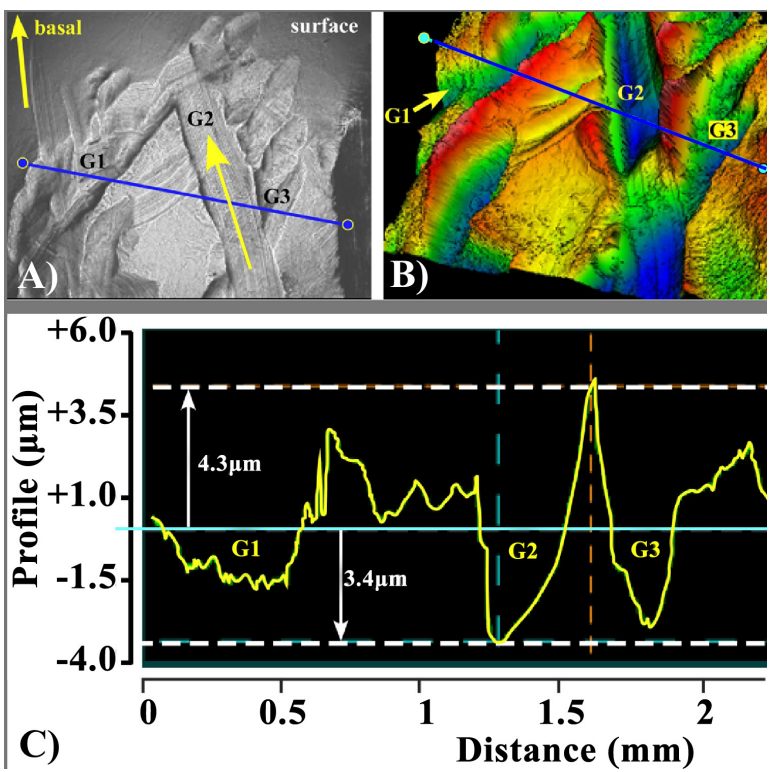

Figure 12. Extensive damage in basal head (dislocating case, Figure 11): (A) SEM image of multiple pits and microgrooves (G1-3) oriented in polar direction; (B) Corresponding WLI image showing profile trace.

discussion purposes, pits will be defined as a $3^{\text {rd }}$-body abrasive-wear mechanism, using acronym "3CO-damage" as the descriptor. However, it is to be noted that we were unable to find any evidence of $\mathrm{CoCr}$ fragments or $\mathrm{CoCr}$ smears representing transfer onto bearing surfaces.

All retrieved MOM bearings revealed microgrooves from 40 to over $100 \mu \mathrm{m}$ wide with raised lips and linearly-striated sidewalls (Figure 13) [54]. Depending on location, these were defined as basal, polar or equatorial microgrooves (Figure 5). Our retrieval study may be the $1^{\text {st }}$ to confirm such "type IV" wear as described in the McKee-Farrar study [40]. In addition, the microgroove characteristics, i.e. $100 \mu \mathrm{m}$ width, longitudinal striations, and plastically-deformed lips (Figure 13, Figure 14) appeared very similar to the large pits (Figure 10, Figure 11) and both will also be considered representative of $3^{\text {rd }}$-body abrasive wear by large CoCr particles (Table 2: 3CO).

Surface "gouges" were described in a retrieval study of large diameter MOM. Gouges ranged up to $1.5 \mathrm{~mm}$ length, $25-75 \mu \mathrm{m}$ width, and $0.25-1 \mu \mathrm{m}$ depth [74]. These were observed on the majority of retrievals and lacked longitudinal striations typical of microgrooves. The authors attributed the gouges on heads to impaction by the cup rims, i.e. a plastic deformation mechanism [74]. Our SEM analysis revealed similar arrays of parallel gouges and surrounding slip bands (Figure 15). These were shallow depressions $1-3 \mathrm{~mm}$ long, showing extensive plastic flow onto surrounding surfaces (Figure 16). For discussion purposes, we shall term femoral-head gouging by the acronym "FHG-damage".

\section{Cup Positions Defining Femoral-Neck Impingements}

Our study of modular MOM retrievals may be unique in that head and cup 


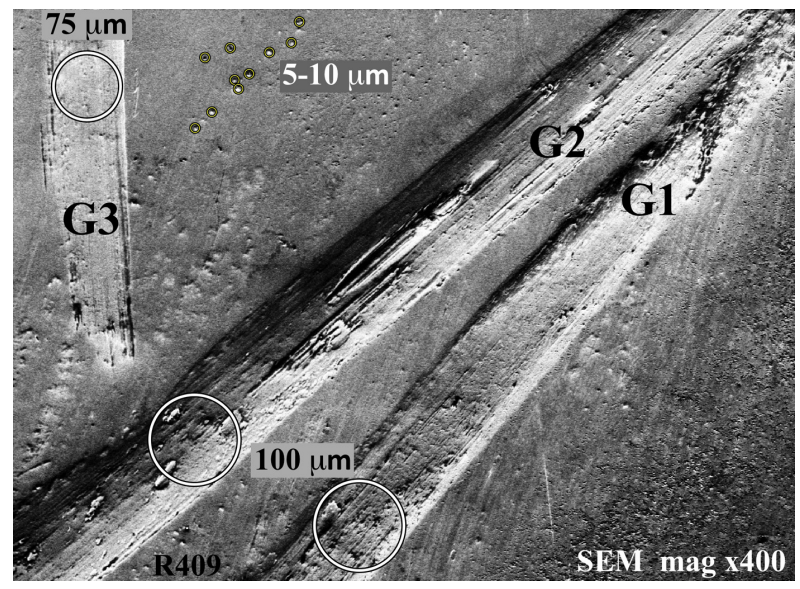

Figure 13. SEM image of twin $100 \mu \mathrm{m}$ microgrooves $(\mathrm{G} 1,2)$ intersected by $70 \mu \mathrm{m}$ microgroove (G3). Note 5 - $10 \mu \mathrm{m}$ carbides dwarfed by microgroove size.

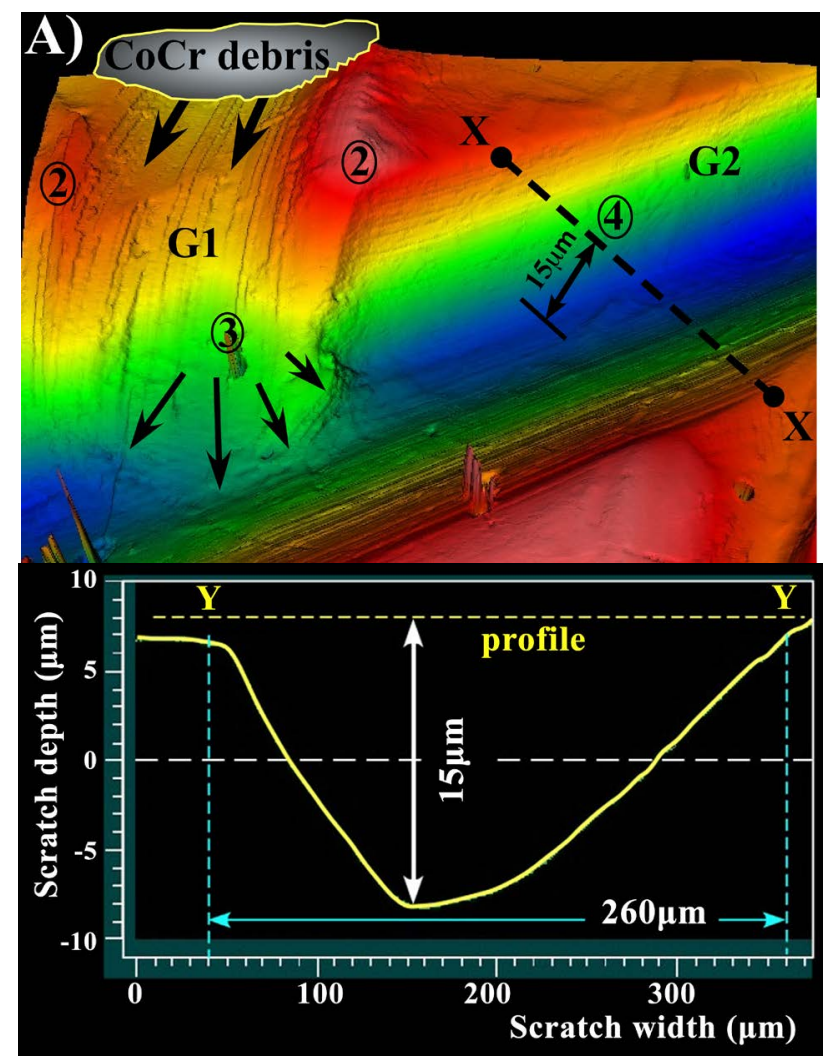

Figure 14. WLI image of $100 \mu \mathrm{m}$ microgroove (G1) intersecting microgroove (G2) with profile track (xx): (A) Hypothetical metal fragment sketched on microgroove-G1 indicating ploughing direction (arrows) and longitudinal striations, plastic deformation of side-walls (2) and avalanche-like flow of CoCr matrix (3); (B) Cross-sectional profile ( $\mathrm{xx}$ ) of microgroove (G2: $260 \mu \mathrm{m}$ wide, $15 \mu \mathrm{m}$ deep).

wear-patterns were mapped to discern how each component was positioned in vivo (Figure 5, Figure 6) [54]. In consequence, it was possible to map the locations of microgrooves with reference to likely neck-on-cup impingement sites (Figure 8, Figure 9). Polar microgrooves crossed the main-wear zone (Figure 5: 


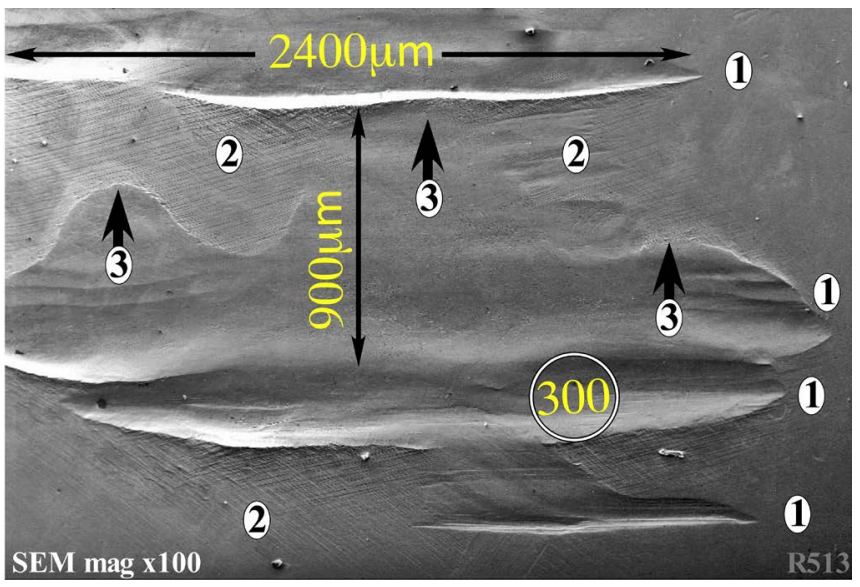

Figure 15. Gouges formed by plastic deformation in basal head (38 $\mathrm{mm} \mathrm{M2a})$ : (1) parallel surface defects; (2) slip planes; (3) plastic-deformation.
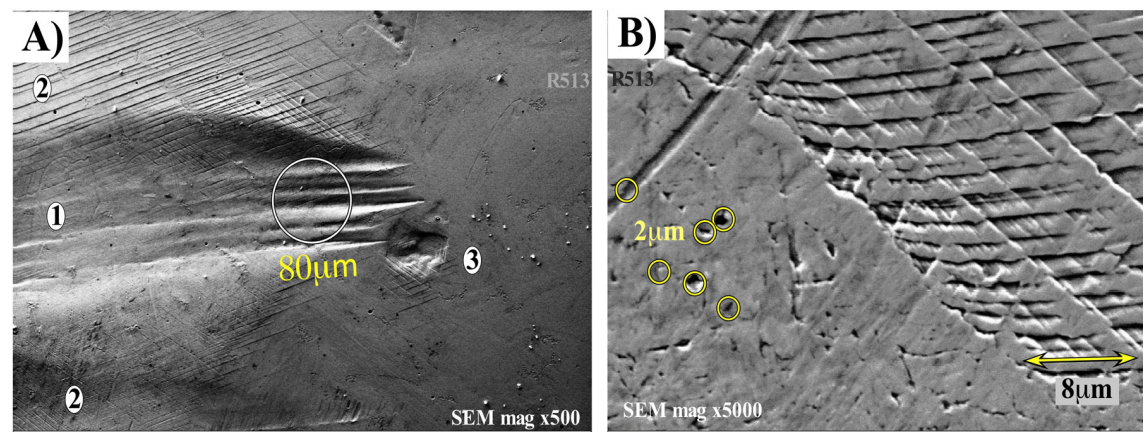

Figure 16. Damaged basal head (38 mm M2a). (A) Large defect (1) and pit (3) surrounded by slip bands (2); (B) Higher magnification of slip bands.

MWZ) and were oriented in a radial direction. Basal microgrooves crossed the non-wear zone (Figure 5: NWZ) and were oriented somewhat radially-oblique. In contrast, equatorial microgrooves tended to align in the transition zone around MWZ-boundaries, their orientation being conspicuously different from basal and polar types. A commonality for all microgrooves was scratch-widths that could span hundreds of microns with raised lips and conspicuous longitudinal striations of sidewalls (Figures 10-14).

The majority of our modular THA bearings were retrieved without mating femoral stems. We therefore used femoral-stem surrogates from inventory when studying likely angles of cup-impingement (Figure $8(C)$ ). The major finding in impingement simulations was that rim-profiles of cups overlaid the basal and polar microgrooves marked on RA and THA heads (Figure 8(C), Figure 8(D), Figure 17). The microgrooves were not always continuous, sometimes obscured by alayer of protein contaminants [63]. Nevertheless, there was generally enough evidence of multiple scratches tracking from base of head into the polar regions of main-wear zone (Figure 6). Some retrievals demonstrated several basal-polarpairings, indicative of multiple impingement sites (Figure 17) [73]. It was noted that equatorial microgrooves around the main-wear zone boundaries 


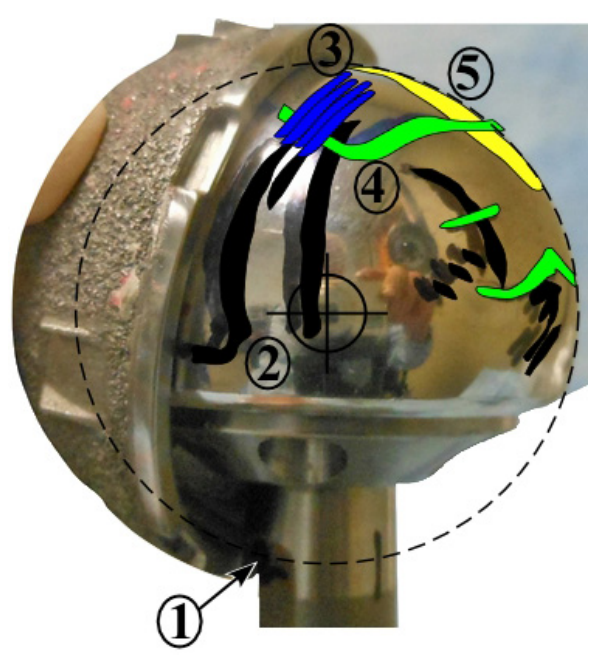

Figure 17. Retrieved head (44mm Magnum) positioned on surrogate femoral stem with impingement on cup rim (1), rim juxtaposed to basal (2: black) and polar (3: blue) microgrooves. Equatorial microgrooves (4: green) and degraded protein layer (5: yellow) as indicated.

were less predictable, could vary from short to considerable length, and were generally not at locations associated with prosthetic impingement (Figure 18).

Our comparisons of both THA and RA femoral components showed essentially similar patterns of microgrooves. The natural bony necks retained with RA femoral shells reduced head: neck ratios and limited the available range of motion [75]. Our microgroove evidence in RA cases revealed that patients routinely compensated by head subluxation [55]. The quandary was in deducing what abrasive wear mechanism formed such large microgrooves in RA and THA bearings? Was it the cup rim or the entrained metal particles? The former would represent Mode- 2 wear as described by McKellop et al. [76] and the latter would represent Mode-3. For discussion purposes, microgrooves produced by the cup rim or entrained metal debris will be differentiated by the acronyms 2CR-damage and 3CR-damage (Table 2).

\section{Evidence of Metal Debris Circulating in the Hip Joint}

SEM analysis demonstrated basal scratches that resembled $100 \mu \mathrm{m}$ wide microgrooves, except they lacked typical longitudinal striations (Figure 19). WLI imaging frequently revealed multiple parallel tracks that represented metal transfer of $1 \mu \mathrm{m}$ thickness with 3 - $5 \mu \mathrm{m}$ peak heights (Figure 20). SEM analysis (Figure 21(A)) and energy dispersive spectroscopy imaging revealed predominantly elemental titanium ( $\mathrm{Ti}$ ) tracking along CoCr surfaces (Figure 21). SEM analysis also revealed longitudinal surface striations exiting some transfer layers. These tracks were therefore considered microgrooves coated by a layer of titanium transfer. Clinical studies of MOM THA have demonstrated that high concentrations of Ti-ions correlated with femoral-neck notching noted in revised Ti6Al4V stems [77]. This unequivocal evidence of metal transfer proved existence of large 


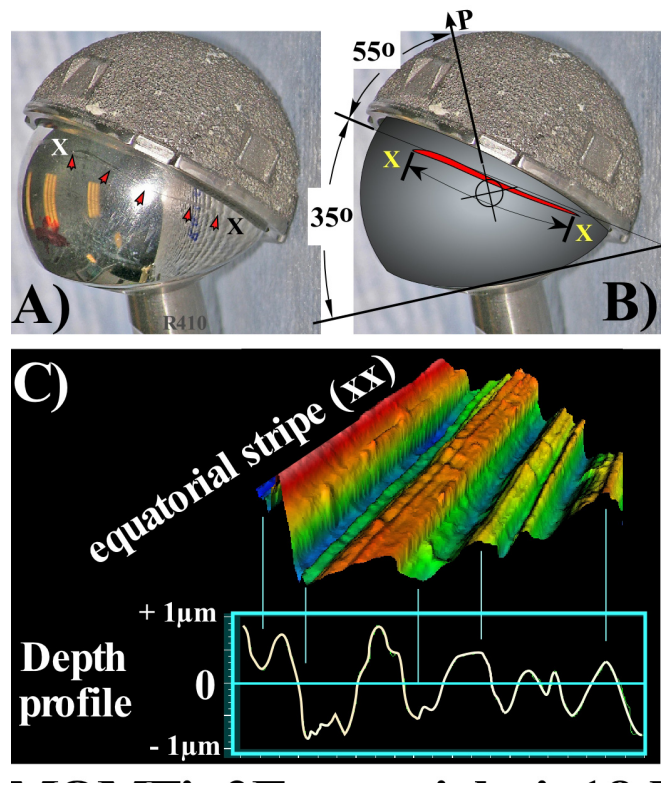

Figure 18. Same worked example (Figure 17) showing cup rim juxtaposed to equatorial microgroove: (A) Visual of long microgroove (red arrowhead track-xx); (B) Cartoon depicting microgroove $>40 \mathrm{~mm}$ length oriented $55^{\circ}$ to polar axis (P); (C) WLI profile showing longitudinal striations ( $2 \mu \mathrm{m}$ peak-to-valley).

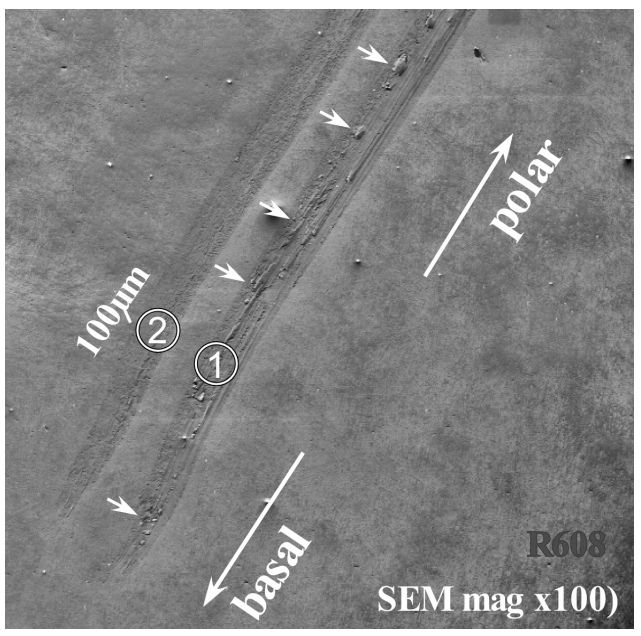

Figure 19. SEM image of twin $100 \mu \mathrm{m}$ microgrooves extending from base of head in polar direction (47 mm ASR XL). Metal transfer (arrows) shown obscuring any longitudinal striations.

circulating Ti6Al4Vfragments, which in turn implicated Ti6Al4V-component impingement (Figure $7(B)$, Figure $7(C)$ ). This SEM evidence was a significant finding because we could not prove the existence of circulating $\mathrm{CoCr}$ fragments or CoCr-transfer. The quandary here was in deducing did the Ti6Al4V particles actually damage the $\mathrm{CoCr}$ surface i.e. created microgrooves, or did they just form a transfer layer that coated pre-existing microgrooves? For discussion purposes, microgrooves produced by abrading Ti6Al4V particles will be termed 3TI-damage and titanium transfer will be termed TTL-damage (Table 2). 


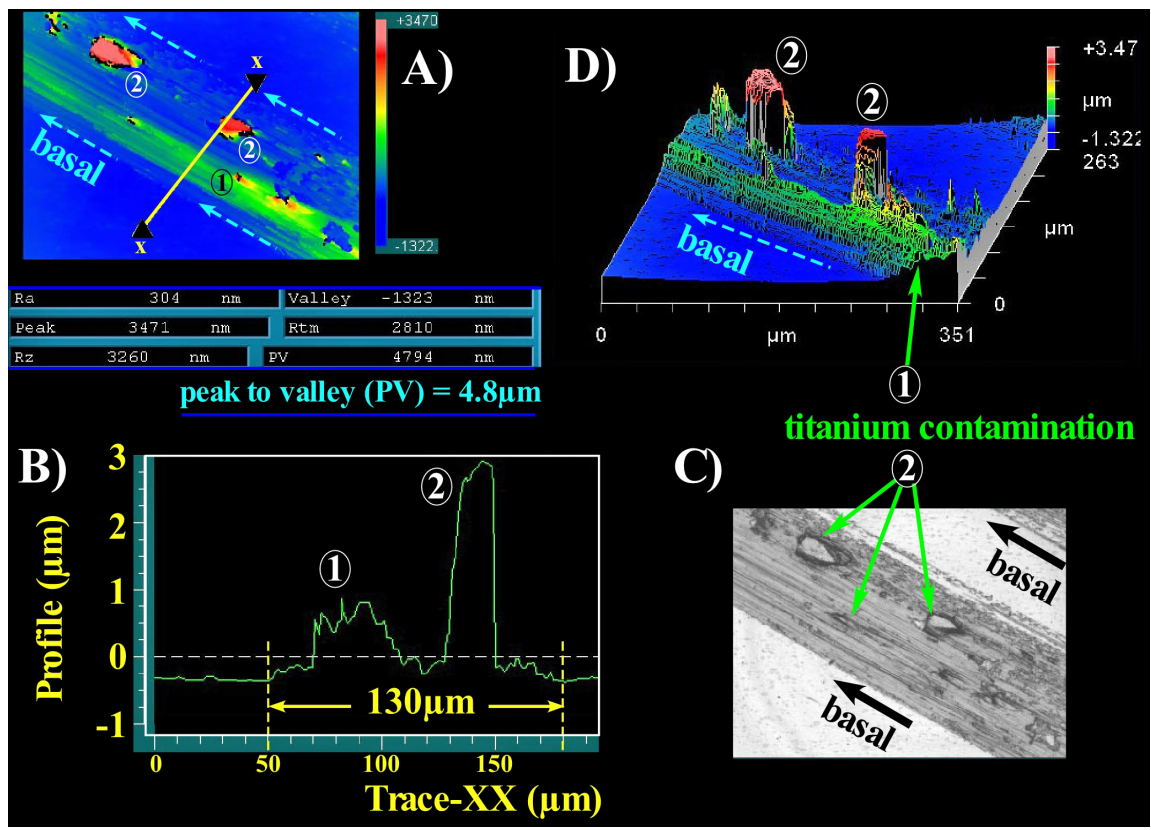

Figure 20. WLI images of twin $100 \mu \mathrm{m}$ tracks with metal transfer (36 mm Pinnacle): (A) Profile trace indicated across transfer peak; (B) Profile of metal transfer, 1 - $4.8 \mu \mathrm{m}$ thick; (C) Light microscopy (in image-A); (D) 3D oblique view of metal transfer (presumed titanium).

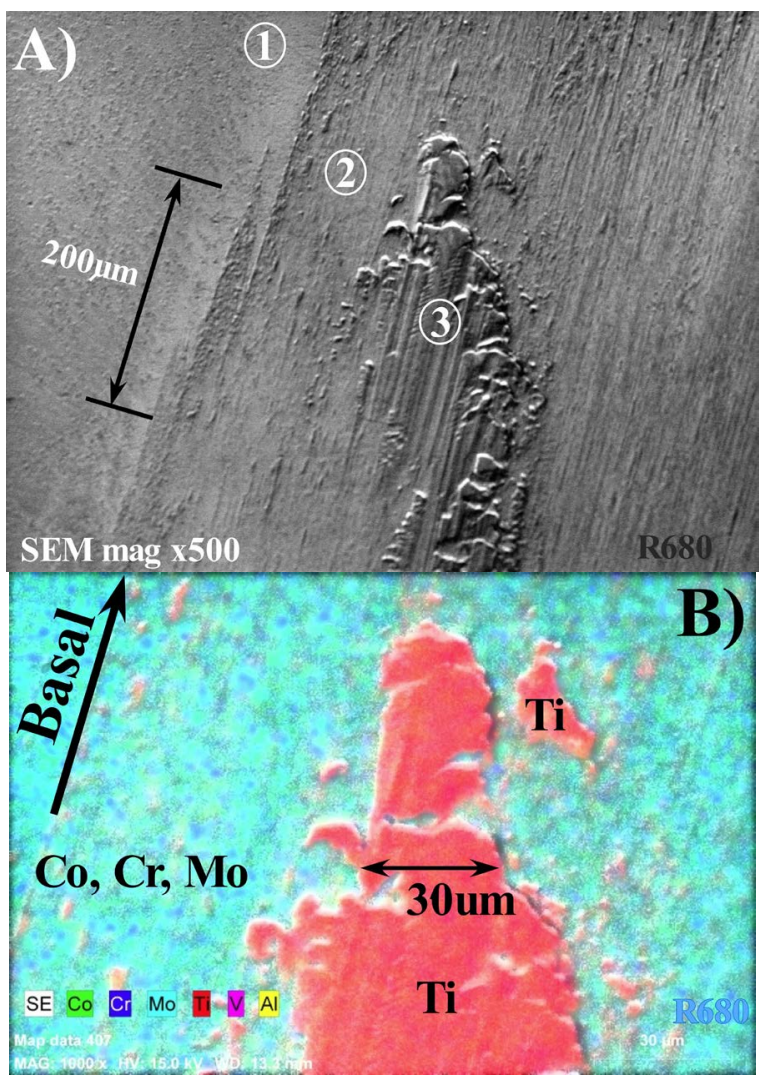

Figure 21. Images of basal microgroove in Figure 20 showing metal transfer: (A) CoCr surface (1) with exposed carbides, (2) metal transfer layer, and (3) metal peaks; (B) Energy dispersive spectroscopy (EDS): titanium smear track crossing CoCr surface. 


\section{EOS Demonstration of Spino-Pelvic/Hip Motions at Impingement Sites}

EOS imaging with 3D-reconstructions in standing and sitting positions provided details of cup functional inclination and anteversion. Knowing femoral anteversion, the important combined anteversion could be determined. EOS images in the functional-standing position of our $1^{\text {st }}$ example show a cup with $40^{\circ}$ inclination but excessive $48^{\circ}$ anteversion (Figure $22(\mathrm{~A})$ ). With $34^{\circ}$ of femoral anteversion, this hip demonstrated $82^{\circ}$ combined-anteversion. Shifting from functional-standing posture (Figure 22(B-1)) into hyperextension (Figure 22(B-2)) determined available range of motion. The cup impingement site was demonstrated by $3 \mathrm{D}$-reconstruction (Figure $22(\mathrm{C})$ ). This patient's $15^{\circ}$ extension ability in functional-standing position proved insufficient (Figure 22(D)) and patient could sense anterior subluxation of the head approaching within $5^{\circ}$ of impingement site (Figure 22(B-2)). However, in functional-sitting posture, the pelvic tilt increased slightly to $25^{\circ}$ thereby providing a $5^{\circ}$ increase in cup anteversion. With $58^{\circ}$ cup inclination in sitting posture, this hip had $63^{\circ}$ of motion before impingement. Thus, EOS imaging demonstrated no limitation in functional-sitting.

EOS images in the functional-standing position ofthe $2^{\text {nd }}$ example showed a cup with $40^{\circ}$ inclination and $35^{\circ}$ anteversion (Figure $23(\mathrm{~A})$ ). Including $15^{\circ}$ of femoral anteversion, this hip demonstrated $50^{\circ}$ of combined anteversion. This patient's standing posture showed $37^{\circ}$ motion available before neck-on-cup posterior impingement for extension testing. Thus, EOS imaging demonstrated no significant limitation in functional-standing. However, in functional-sitting position (Figure $23(\mathrm{~B})$ ), this patient had only $22^{\circ}$ of flexion arc. This hip impinged

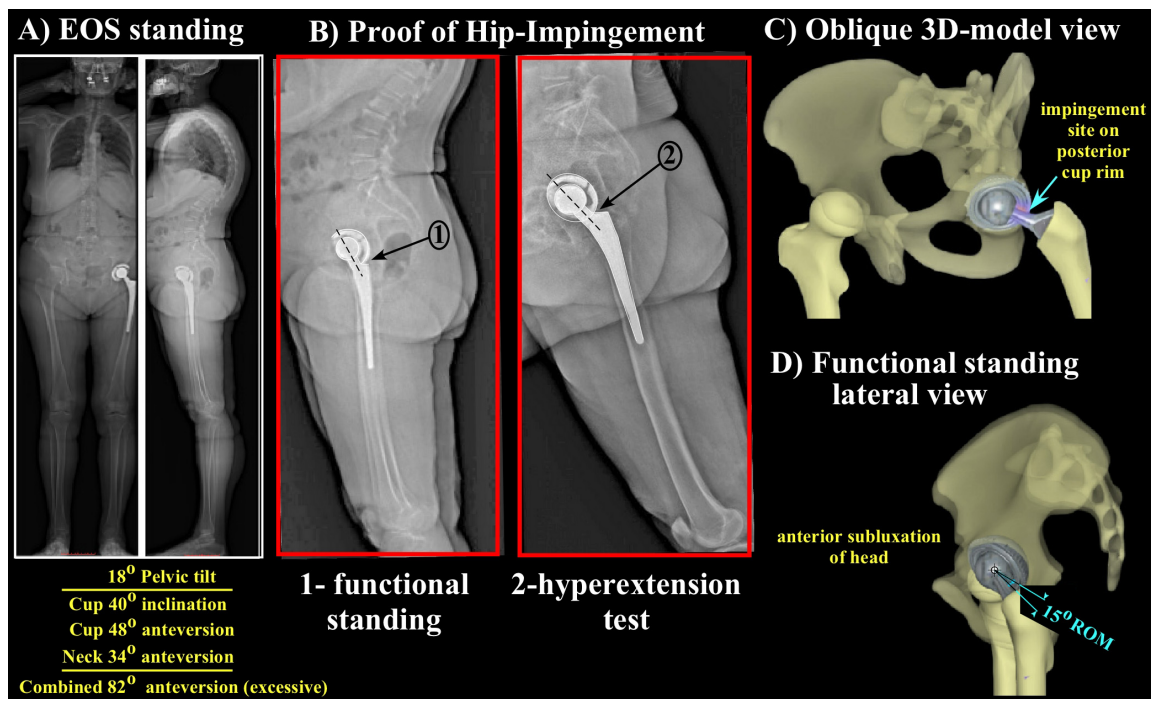

Figure 22. EOS-reconstructions with cup-impingement site in functional-standing: (A) frontal and lateral images in functional-standing posture; (B) functional standing (1) and impingement revealed in extension-test (2); (C) Oblique 3D-reconstruction, femoral neck close to posterior cup rim; (D) Lateral reconstruction, $15^{\circ}$ arc before neck impinged posteriorly. 


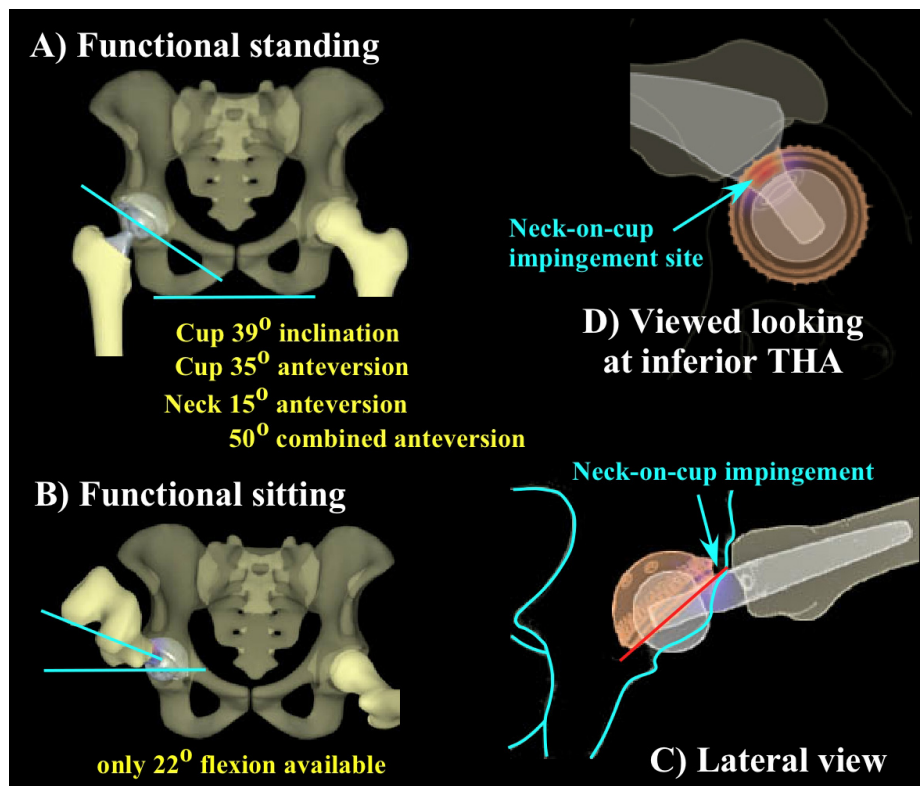

Figure 23. EOS-reconstructions with cup-impingement site in functional-standing: (A) frontal and lateral images in functional-standing posture; (B) functional standing (1) and impingement revealed in extension-test (2); (C) Oblique 3D-reconstruction, femoral neck close to posterior cup rim; (D) Lateral reconstruction, $15^{\circ}$ arc before neck impinged posteriorly.

and subluxed, as demonstrated in the corresponding lateral (Figure 23(C)) and inferior views (Figure 23(D)).

\section{Discussion of MOM Wear Concepts}

As part of our analysis of large diameter MOM retrievals, we defined eight potential types of damage (Table 2). The unequivocal evidence of circumferentially-notched femoral-necks (Figures 7-9) represented, 1) NAR-damage (Table 2) that could only have occurred over millions of gait cycles, and 2) notches that unequivocally defined sites of prosthetic-impingement (Figure 8(C), Figure 9). We recognize that a loose and migrating metal cup could also produce damage in failing hip-procedures. However, it would be difficult to conceive that loose cups, patients suffering from multiple dislocations [71], or even inadvertent damage during surgery, could produce such neck notching. Thus, our conclusion was that neck notches represented abrasion by the cup rim, an unintended consequence representative of 2-body abrasion, thus confirming our $2^{\text {nd }}$ hypothesis.

Impingement has been a frequently-raised concern in McKee-Farrar studies [28] [39] [40] [41] [78]. Our current focus on impingement in modular MOM bearings was based on wear analysis of the "fixed-head" McKee-Farrar design [40]. Howie et al. described "impingement marks" in nine of 29 THA and noted extrusion of metal fragments due to sub-surface fatigue. However, in our opinion, their landmark finding lay in the description of "type-IV" wear patterns. These were described as deep and parallel wear tracks that spanned approx- 
imately $100 \mu \mathrm{m}$ width on highly-reflective head surfaces. Ours may be the first to confirm this type-IV wear evidence. We found ample evidence of $100 \mu \mathrm{m}$ wide scratches (and larger) and similar sized pitting. We termed these type-IV scratches as "microgrooves". The microgrooves were significantly larger than anything described in current MOM literature and dwarfed the scale of exposed carbide formations frequently attributed to scratch formations (Figure 1, Figure 10, Figure 13, Figure 21(A)) [28] [78]. Microgroove characteristics included long curvilinear tracks, raised lips (evidence of plastic deformation), and longitudinal striations (evidence of ploughing/abrasion). Salient observations made from this review of microgroove formations included;

1) Curvilinear microgrooves crossing the main-wear zones in polar areas of femoral heads had to be forming repeatedly, otherwise they would have been eradicated by the hip's normal and routine wear process.

2) Neck-on-cup prosthetic impingement (NAR-damage) appeared to be the sole mechanism that could produce observed consistency in siting of basal/polar microgrooves. This was supportive of hypothesis-5.

3) The variability of equatorial microgrooves around the periphery of main-wear zones was not related to prosthetic-impingement sites. Most likely these microgrooves represented impingement with soft-tissues, a possible confirmation of hypothesis- 6 .

4) The large pits and linear microgrooves crossing basal head areas appeared an enigma, since these were designated "non-wear" regions. However, as others have described, these areas would represent the ingress sites of circulating metal particles [46] [79]. As noted, these were not areas of normal head-wear and therefore basal surfaces were well preserved, confirminghypothesis- 4 .

5) Cup microgrooves could only have been formed by circulating metal particles, and therefore represented $3^{\text {rd }}$-body abrasive wear, confirminghypothesis- 8 .

6) The circular shape of femoral wear-patterns (Figure 6) was not duplicated in cups. The cup wear-patterns were mostly eccentrically positioned around arcs of cup rim (Figure 24).

7) Large arcs of cup wear represent "edge-loading" may be representative of head subluxation or sub-optimal cup positioning.

What we did not find was any evidence of tracks that would have represented transfer of $\mathrm{CoCr}$ debris. We had to infer the existence of $\mathrm{CoCr}$ particles from pit and scratch morphologies (Figure 2, Figures 10-12, Figure 14) that revealed raised lips (plastic-deformation) and linear striations (abrasion). These features represented the classic signature of $3^{\text {rd }}$ body abrasion by hard particles. Nevertheless, our SEM/EDS analyses did confirm layers of Ti6Al4V contamination smeared over similar-sized microgrooves (Table 2: TTL damage). Titanium transfer onto head microgrooves was also commented on in a previous SEM study (see Band et al., figs. 6.38, 6.39) [80]. These authors speculated that Ti-transfer could have originated from debris released from ingrowth-surfaces. However, in THA devices with Ti6Al4V-shells or Ti6Al4V-stems, titanium 


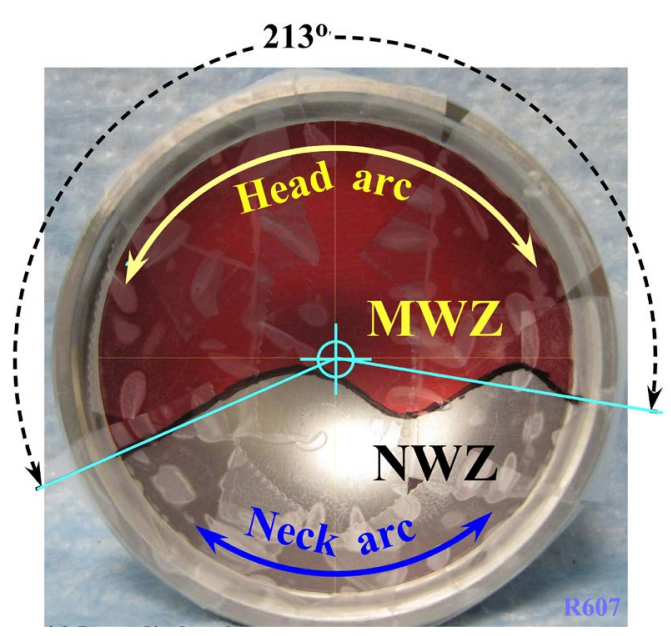

Figure 24. Position of main-wear zone (MWZ) representative of superior quadrant in retrieved cup (46.5 mm ASR). Cup rim-wear produced by subluxing head extends around large $\operatorname{arc}\left(213^{\circ}\right)$ while femoral neck rotated against contra-rim (neck arc).

particles could equally originate from prosthetic impingement (Figure 7, Figure 8). The Ti-ion concentrations detected in vivo [81] and titanium smears on $\mathrm{CoCr}$ retrievals represented unequivocal evidence of 1) prosthetic impingement onTi6Al4V components, 2) release of Ti6Al4V particles, 3) ingress of circulating Ti6Al4V particles into MOM bearings, thereby forming 4) Ti6Al4V transfer layers that resembled microgrooves. We demonstrated in the laboratory setting that introduction of both $\mathrm{Ti} 6 \mathrm{Al} 4 \mathrm{~V}$ and $\mathrm{CoCr}$ particles produced microgrooves in CoCr surfaces (Table 2: 3CO, 3TI) and provoked adverse wear in simulator tests [82] [83]. This accumulation of evidence therefore is supportive of our 3rd hypothesis that hip impingement and head subluxation represent major risks for release of large metal fragments.

The unique finding in our simulated "femoral-neck/cup-rim" impingements was that cup rims invariably followed tracks of basal and polar microgrooves (Figure 8(C), Figure 17, Figure 18), confirming hypothesis-5. Two possibilities were that, 1) cyclic loading by the cup rim produced plastic deformation represented by gouge defects (Table 2: FHG-damage) [74] or 2) cyclic abrasive motion produced microgrooves (Table 2: 2CR-damage). It was equally possible that circulating metal fragments trapped under the cup rim moved with it, their ploughing action producing microgrooves (Table 2: 3CR-damage). The similar morphology of large pits (Figures 10-12) and microgrooves (Figure 13 \& Figure 14) favored $3^{\text {rd }}$-body wear (Table 2: $3 \mathrm{CR}$ ). This was supported by evidence of cup microgrooves, wherein the only possibility was abrasion by circulating metal particles. Also compelling in an unrelated study was retrieval evidence of metal particles (126 $\mu \mathrm{m}$ avg. size) embedded in polyethylene cup surfaces [58]. Such correlations appeared very supportive of a ${ }^{\text {rd }}$-body wear hypothesis. Nevertheless, the evidence of microgrooves of considerable length aligned with cup-rim profiles was also suggestive of 2-body abrasion (Table 2: 2CR). Thus, hypothesis-7 appears satisfactory, that head microgrooves represent 2-body and 
3-body wear mechanisms created by the cup rim during millions of hip impingements.

There was ample evidence of plastic-deformation in modular $\mathrm{CoCr}$ bearings. The raised side-walls of microgrooves and the presence of slip bands on scratch shoulders attested to plastic-flow in damaged $\mathrm{CoCr}$ surfaces. Intersections of crossing microgrooves provided further evidence of cold-flow (Figure 14). Larger gouges surrounded by arrays of slip bands represented evidence of plastically-deformed defects [74]. These we also found and could be attributable to indents made by an impinging cup rim (Table 2: 2CR) or damage produced during revision surgery (Table 2: 2OR). Either way, we were not impressed that these were as common or consistently present as the $100 \mu \mathrm{m}$ microgroove formations. Therefore, we support ouroverriding $3^{\text {rd }}$-body wear scenario, that impingement and head subluxation trigger the release of metal fragments. These metal particles will readily circulate in the hip during patient gait and ingress between moving bearings [46] [49] [84]. There is also the added risk with highly-inclined and highly-anteverted cups. Such patients are likely to have more frequent and more adverse THA impingement episodes than normal.

The concept of hip impingement occurring without the patient's awareness we termed a repetitive sub-clinical subluxation (RSS) phenomenon [73] [85]. An appropriately-positioned acetabular cup will reduce the risk of the metal acetabular shell impinging on a metal femoral-neck (Table 2: NAR-damage). However, with hip impingement and subluxation there remains the risk of the femoral head being damaged. It is to be noted that laboratory simulations of steeply-inclined cups [20] [64] did not produce black lubricants or the adverse MOM wear described clinically. In contrast, introduction of metal particles in each $1 / 4$-million cycle interval of our MOM debris studies immediately turned the yellow lubricants black [83]. Therefore, we find our overriding scenario of $3^{\text {rd }}$-body wear supported, that hip impingement and head subluxation release metal fragments that trigger the advent of adverse wear in MOM bearings.

It is conceivable that even one hip impingement could have $3^{\text {rd }}$-body wear implications over ensuing millions of gait cycles. Metal particles can readily circulate in the hip during patient gait and ingress between moving bearing surfaces [46] [49] [84]. From theoretical considerations, large-diameter MOM bearings in motion may develop lubricating films of $7-30 \mathrm{~nm}$ thickness [4]. However, such proteinaceous layers would offer no protection to the ingress of metal particles some 3000-times larger. It is noted that contemporary debris descriptions in MOM simulator and retrieval studies [8] [19] [86] ascribed only nanometer size to $\mathrm{CoCr}$ particles. It is to be noted that the life cycle of large $\mathrm{CoCr}$ fragments hundreds of microns in size disintegrating and ionizing in hip-joints remains virtually unknown. Thus, it is our hypothesis that "hard-on-hard" bearings represented a particularly harsh environment for circulating metal particles. We postulated [54] that disintegration of one $100 \mu \mathrm{m}$ size CoCr fragment could produce 8000 particles of nanometer size and that such fine debris likely 
represented the "self-polishing" mechanism attributed to MOM bearings [8] [39] [41] [87] [88]. In contrast, THA designs with metal-on-polyethylene (MPE) bearings have a soft surface that can readily absorb $3^{\text {rd }}$-body debris including large metal particles [49] [84]. Thus, the accumulating evidence is persuasive that it is the production of large metal fragments that triggers adverse wear. This we would consider proof that, unlike more forgiving MPE bearings, MOM bearings are extremely sensitive to the ingress of metal debris.

The limitations of this study are common to other retrieval studies. Components were seldom received with any markings to indicate position at revision surgery. Thus, we relied on mapping of wear-patterns to deduce in-vivo positioning. Retrieval of femoral stems proved to be an infrequent occurrence in these $2^{\text {nd }}$ generation MOM designs. Hence, we lacked evidence of femoral impingement. We also had to rely on surrogate femoral stems of the same brand for neck-cup impingement studies such that the equivalent size neck/femoral stem would simulate the original device. In addition, these data relate only to failed MOM bearings. The visual and microscopic evidence of large pits and polar microgrooves persisting in habitual wear patterns (main-wear zones) denoted repetitive and consistent episodes of hip impingement and subluxation in these retrievals. However, we have no knowledge of whether such wear mechanisms either contributed directly to the failures, or would be present in more successful cases.

Hip impingement and subluxation of the femoral head are key concepts in understanding "normal" functioning of THA and predicting the risk of adverse conditions. In the activities of daily living, patients are continually implementing a succession of standing and sitting postures. The roles of 1) hyperextension, and 2) combined flexion and rotation, reflect the importance and recognition of "critical contact zones" occurring between femoral neck and rim of the acetabular cup. Our EOS studies showed that THA impingement and head subluxation can be demonstrated in patient's functional postures, notably standing, full extension and sitting, and can be present even when the cup is positioned in the "safe zone". [60] [89] EOS results confirmed our $1^{\text {st }}$ hypothesis and this was regardless of whether THA designs had $28 \mathrm{~mm}$ heads (Figure $8(\mathrm{C})$ ) or larger (Figure 9). These EOS observations supporting the analysis of retrieved MOM bearings can now be carried into clinical studies of THA devices to discern which patients have normal function and which risk impingement, subluxation and dislocation.

\section{Conclusion}

By consolidating the impingement/wear evidence from retrieved MOM bearings, 8-risk scenarios were identified. Neck/cup impingement has been confirmed by 1) circumferential scratches and notches on femoral stems, and 2) $\mathrm{mi}$ crogrooves dominating specific locations on femoral heads. In basal and polar regions of the femoral head, these represented sites of prosthetic impingement. 
In equatorial regions of the femoral head, we hypothesize that these represented impingement sites with soft-tissues. This retrieval evidence demonstrates that the rim of an impinging CoCr cup can result in abrasive damage on the femoral head (2CR: 2-body wear; 3CR, $3^{\text {rd }}$-body wear) as well as femoral-neck notching (Table 2: NAR, $3^{\text {rd }}$ body wear). In this regard, we were surprised to find that such self-evident impingement damage on MOM bearings, as first described by Howie et al. [40] apparently has received no attention over the past 13 years. This applies to some metal-backed polyethylene cups (Figure 9) as well as CoCr cup designs. It is noted that metal-backed cup designs offer the surgeon many options. Nevertheless, the National Joint Registries have shown that cemented polyethylene cups have consistently better clinical outcomes than non-cemented cups, i.e. the metal-backed cups have not been as forgiving [26] [90]. EOS imaging and associated 3D-reconstructions will also aid our understanding of the retrieval data and better conceptualizing of optimal component positioning in patients with differing complexities of spino-pelvic mobility. In turn, EOS imaging of implant positioning in the clinical setting will offer an improved diagnosis with respect to patient's functional postures and help determine risk of failure.

\section{Acknowledgements}

This review of metal-on-metal hip wear mechanics was funded in part by Empire Orthopedics (Colton, CA) and by the Arthroplasty for Arthritis Charity (UK charity\# 1051165). The original foundational projects on MOM simulator and retrieval analyses were funded by FDA contract, "Analysis and Validation of Wear and Corrosion Performance of Metal on Metal Hip Explants" (FDA-1090360). The authors acknowledge the staff of Zygo Corporation's Western Regional Offices (Fremont, CA, Tucson, AZ) for their technical support. Grateful thanks are also due to Michelle Burgett, T. Halim, P. Williamsand D. Sufficool (DARF Center and Loma Linda University) and R. Moran (Moran Innovations, Redlands) for technical assistance. Thanks are due to the DJO Group, Austin, TX, for their considerable donation of MOM bearings.

\section{Conflicts of Interest}

The authors declare no conflicts of interest regarding the publication of this paper.

\section{References}

[1] McMinn, D., Treacy, R., Lin, K. and Pynsent, P. (1996) Metal on Metal Surface Replacement of the Hip. Experience of the McMinn Prothesis. Clinical Orthopaedics and Related Research, 329, S89-98. https://doi.org/10.1097/00003086-199608001-00009

[2] Amstutz, H.C., Campbell, P., McKellop, H., Schmalzreid, T.P., Gillespie, W.J., Howie, D., Jacobs, J., Medley, J. and Merritt, K. (1996) Metal on Metal Total Hip Replacement Workshop Consensus Document. Clinical Orthopaedics and Related Research, 329, S297-303. https://doi.org/10.1097/00003086-199608001-00027 
[3] Dowson, D. (2006) Tribological Principles in Metal-on-Metal Hip Joint Design. The Proceedings of the Institution of Mechanical Engineers [H], 220, 161-171. https://doi.org/10.1243/095441105X63255

[4] Dowson, D. and Jin, Z.M. (2006) Metal-on-Metal Hip Joint Tribology. Proceedings of the Institution of Mechanical Engineers [H], 220, 107-118. https://doi.org/10.1243/095441105X69114

[5] Amstutz, H.C. and Grigoris, P. (1996) Metal on Metal Bearings in Hip Arthroplasty. Clinical Orthopaedics and Related Research, 329, S11-34. https://doi.org/10.1097/00003086-199608001-00003

[6] Kamali, A. (2009) Hip Joint Tribology. In: McMinn D., Ed., Modern Hip Resurfacing, Springer, Berlin, 79-89. https://doi.org/10.1007/978-1-84800-088-9_4

[7] Smith, S.L., Dowson, D. and Goldsmith, A.A.J. (2001) The Effect of Diametral Clearance, Motion and Loading Cycles upon Lubrication of Metal-on-Metal Total Hip Replacements. Proceedings of the Institution of Mechanical Engineers [H], 215, 1-5. https://doi.org/10.1243/0954411011533724

[8] Streicher, R.M., Semlitsch, M., Schon, R., Weber, H. and Rieker, C. (1996) Metal-on-Metal Articulation for Artificial Hip Joints: Laboratory Study and Clinical Results. Proceedings of the Institution of Mechanical Engineers [H], 210, 223-232. https://doi.org/10.1243/PIME_PROC_1996_210_416_02

[9] Yew, A., Udofia, I., Jagatia, M. and Jin, Z.M. (2004) Analysis of Elastohydrodynamic Lubrication in McKee-Farrar Metal-on-Metal Hip Joint Replacement. Proceedings of the Institution of Mechanical Engineers [H], 218, 27-34. https://doi.org/10.1243/095441104322807721

[10] Udofia, I.J. and Jin, Z.M. (2003) Elastohydrodynamic Lubrication Analysis of Metal-on-Metal Hip-Resurfacing Prostheses. Journal of Biomechanics, 36, 537-544. https://doi.org/10.1016/S0021-9290(02)00422-0

[11] Amstutz, H.C., Campbell, P.A. and Le Duff, M.J. (2004) Fracture of the Neck of the Femur after Surface Arthroplasty of the Hip. The Journal of Bone and Joint Surgery, 86-A, 1874-1877. https://doi.org/10.2106/00004623-200409000-00003

[12] Sharma, H., Rana, B., Watson, C., Campbell, A.C. and Singh, B.J. (2005) Femoral Neck Fractures Complicating Metal-on-Metal Resurfaced Hips: A Report of 2 Cases. Journal of Orthopaedic Surgery (Hong Kong), 13, 69-72. https://doi.org/10.1177/230949900501300112

[13] Beaule, P.E., Campbell, P. and Shim, P. (2006) Femoral Head Blood Flow during Hip Resurfacing. Clinical Orthopaedics and Related Research, 456, 148-152.

https://doi.org/10.1097/01.blo.0000238865.77109.af

[14] Campbell, P., Beaule, P.E., Ebramzadeh, E., LeDuff, M., De Smet, K., Lu, Z. and Amstutz, H.C. (2006) The John Charnley Award: A Study of Implant Failure in Metal-on-Metal Surface Arthroplasties. Clinical Orthopaedics and Related Research, 453, 35-46. https://doi.org/10.1097/01.blo.0000238777.34939.82

[15] O’Neill, M., Beaule, P.E., Bin Nasser, A., Garbuz, D., Lavigne, M., Duncan, C., Kim, P.R. and Schemitsch, E. (2009) Canadian Academic Experience with Metal-on-Metal Hip Resurfacing. Bulletin of the NYU Hospital for Joint Diseases, 67, 128-131.

[16] McKellop, H., Park, S., Chiesa, R., Doorn, P., Lu, B., Normand, P., Grigoris, P. and Amstutz, H. (1996) In Vivo Wear of 3 Types of Metal on Metal Hip Prostheses during 2 Decades of Use. Clinical Orthopaedics and Related Research, 329S, 128-140. https://doi.org/10.1097/00003086-199608001-00013 
[17] Schmalzried, T.P., Szuszczewicz, E.S., Akizuki, K.H., Petersen, T.D. and Amstutz, H.C. (1996) Factors Correlating with Long Term Survival of McKee-Farrar Total Hip Prostheses. Clinical Orthopaedics and Related Research, No. 329, S48-S59. https://doi.org/10.1097/00003086-199608001-00005

[18] Weber, B.G. (1997) Articulating Metal Interfaces. Orthopedics, 20, 811-814.

[19] Leslie, I., Williams, S., Brown, C., Isaac, G., Jin, Z., Ingham, E. and Fisher, J. (2008) Effect of Bearing Size on the Long-Term Wear, Wear Debris, and Ion Levels of Large Diameter Metal-on-Metal Hip Replacements-An in Vitro Study. Journal of Biomedical Materials Research Part B: Applied Biomaterials, 87, 163-172. https://doi.org/10.1002/jbm.b.31087

[20] Angadji, A., Royle, M., Collins, S.N. and Shelton, J.C. (2009) Influence of Cup Orientation on the Wear Performance of Metal-on-Metal Hip Replacements. Proceedings of the Institution of Mechanical Engineers, Part H, 223, 449-457. https://doi.org/10.1243/09544119JEIM518

[21] Bowsher, J.G., Clarke, I.C., Williams, P.A. and Donaldson, T.K. (2009) What Is a "Normal" Wear Pattern for Metal-on-Metal Hip Bearings? Journal of Biomedical Materials Research Part B: Applied Biomaterials, 91, 297-308. https://doi.org/10.1002/jbm.b.31403

[22] Affatato, S., Spinelli, M., Zavalloni, M., Leardini, W. and Viceconti, M. (2008) Predictive Role of the Lambda Ratio in the Evaluation of Metal-on-Metal Total Hip Replacement. Proceedings of the Institution of Mechanical Engineers, Part H, 222, 617-628. https://doi.org/10.1243/09544119JEIM370

[23] Lee, R., Essner, A. and Wang, A. (2008) Tribological Considerations in Primary and Revision Metal-on-Metal Arthroplasty. The Journal of Bone and Joint Surgery, 90, 118-124. https://doi.org/10.2106/JBJS.H.00531

[24] Langton, D.J., Sprowson, A.P., Joyce, T.J., Reed, M., Carluke, I., Partington, P. and Nargol, A.V. (2009) Blood Metal Ion Concentrations after Hip Resurfacing Arthroplasty: A Comparative Study of Articular Surface Replacement and Birmingham Hip Resurfacing Arthroplasties. The Journal of Bone and Joint Surgery, 91, 1287-1295. https://doi.org/10.1302/0301-620X.91B10.22308

[25] Langton, D., Jameson, S., Joyce, T., Hallab, N., Natu, S. and Nargol, A. (2010) Early Failure of Metal-on-Metal Bearings in Hip Resurfacing and Large-Diameter Total Hip Replacement. A Consequence of Excess Wear. Journal of Bone and Joint Surgery, 92, 38-46. https://doi.org/10.1302/0301-620X.92B1.22770

[26] Karachalios, T., Komnos, G. and Koutalos, A. (2018) Total Hip Arthroplasty: Survival and Modes of Failure. EFORT Open Reviews, 3, 232-239. https://doi.org/10.1302/2058-5241.3.170068

[27] Langton, D., Joyce, T., Jameson, S., Lord, J., Van Orsouw, M., Holland, J., Nargol, A. and De Smet, K. (2011) Adverse Reaction to Metal Debris Following Hip Resurfacing. Journal of Bone and Joint Surgery, 93, 164-171. https://doi.org/10.1302/0301-620X.93B2.25099

[28] Munemoto, M., Grammatopoulos, G., Tanaka, Y., Gibbons, M. and Athanasou, N.A. (2017) The Pathology of Failed McKee-Farrar Implants: Correlation with Modern Metal-on-Metal-Implant Failure. Journal of Materials Science, 28, 66.

[29] De Haan, R., Pattyn, C., Gill, H.S., Murray, D.W., Campbell, P.A. and De Smet, K. (2008) Correlation between Inclination of the Acetabular Component and Metal Ion Levels in Metal-on-Metal Hip Resurfacing Replacement. The Journal of Bone and Joint Surgery, 90, 1291-1297. https://doi.org/10.1302/0301-620X.90B10.20533

[30] Brodner, W., Grubl, A., Jankovsky, R., Meisinger, V., Lehr, S. and Gottsauner-Wolf, 
F. (2004) Cup Inclination and Serum Concentration of Cobalt and Chromium after Metal-on-Metal Total Hip Arthroplasty. The Journal of Arthroplasty, 19, 66-70. https://doi.org/10.1016/j.arth.2004.09.003

[31] Marker, M., Grubl, A., Riedl, O., Heinze, G., Pohanka, E. and Kotz, R. (2008) Metal-on-Metal Hip Implants: Do They Impair Renal Function in the Long-Term? A 10-Year Follow-Up Study. Archives of Orthopaedic and Trauma Surgery, 128, 915-919. https://doi.org/10.1007/s00402-007-0466-9

[32] De Smet, K., De Haan, R., Calistri, A., Campbell, P.A., Ebramzadeh, E., Pattyn, C. and Gill, H.S. (2008) Metal Ion Measurement as a Diagnostic Tool to Identify Problems with Metal-on-Metal Hip Resurfacing. The Journal of Bone and Joint Surgery, 90, 202-208. https://doi.org/10.2106/JBJS.H.00672

[33] Garbuz, D.S., Tanzer, M., Greidanus, N.V., Masri, B.A. and Duncan, C.P. (2010) The John Charnley Award: Metal-on-Metal Hip Resurfacing versus Large-Diameter Head Metal-on-Metal Total Hip Arthroplasty: A Randomized Clinical Trial. Clinical Orthopaedics and Related Research, 468, 318-325. https://doi.org/10.1007/s11999-009-1029-x

[34] Underwood, R.J., Zografos, A., Sayles, R.S., Hart, A. and Cann, P. (2012) Edge Loading in Metal-on-Metal Hips: Low Clearance Is a New Risk Factor. Proceedings of the Institution of Mechanical Engineers, Part H, 226, 217-216. https://doi.org/10.1177/0954411911431397

[35] Morlock, M.M., Bishop, N.E., Zustin, J., Hahn, M., Ruther, W. and Amling, M. (2008) Modes of Implant Failure after Hip Resurfacing: Morphological and Wear Analysis of 267 Retrieval Specimens. The Journal of Bone and Joint Surgery, 90, 89-95. https://doi.org/10.2106/JBJS.H.00621

[36] Langton, D.J., Sidaginamale, R., Lord, J.K., Nargol, A.V. and Joyce, T.J. (2012) Taper Junction Failure in Large-Diameter Metal-on-Metal Bearings. Bone \& Joint Research, 1, 56-63. https://doi.org/10.1302/2046-3758.14.2000047

[37] Goldberg, J.R., Gilbert, J.L., Jacobs, J.J., Bauer, T.W., Paprosky, W. and Leurgans, S. (2002) A Multicenter Retrieval Study of the Taper Interfaces of Modular Hip Prostheses. Clinical Orthopaedics and Related Research, No. 401, 149-161. https://doi.org/10.1097/00003086-200208000-00018

[38] Panagiotidou, A., Meswania, J., Hua, J., Muirhead-Allwood, S., Hart, A. and Blunn, G. (2013) Enhanced Wear and Corrosion in Modular Tapers in Total Hip Replacement Is Associated with the Contact Area and Surface Topography. Journal of Orthopaedic Research, 12, 2032-2039. https://doi.org/10.1002/jor.22461

[39] Walker, P.S., Salvati, E. and Hotzler, R.K. (1974) The Wear on Removed McKee-Farrar Total Hip Prostheses. The Journal of Bone and Joint Surgery, 56A, 92-100. https://doi.org/10.2106/00004623-197456010-00011

[40] Howie, D.W., McCalden, R.W., Nawana, N.S., Costi, K., Pearcy, M.J. and Subramanian, C. (2005) The Long-Term Wear of Retrieved McKee-Farrar Metal-on-Metal Total Hip Prostheses. The Journal of Arthroplasty, 3, 350-357. https://doi.org/10.1016/j.arth.2004.09.028

[41] McKellop, H., Park, S.H., Chiesa, R., Doorn, P., Lu, B., Normand, P., Grigoris, P. and Amstutz, H. (1996) In Vivo Wear of Three Types of Metal on Metal Hip Prostheses during Two Decades of Use. Clinical Orthopaedics and Related Research, No. 329, S128-S140. https://doi.org/10.1097/00003086-199608001-00013

[42] Iida, H., Kaneda, E., Takada, H., Uchida, K., Kawanabe, K. and Nakamura, T. (1999) Metallosis Due to Impingement between the Socket and the Femoral Neck in a Metal-on-Metal Bearing Total Hip Prosthesis. A Case Report. The Journal of Bone 
and Joint Surgery, 81, 400-403. https://doi.org/10.2106/00004623-199903000-00013

[43] Clarke, I.C., Lazennec, J.Y., Brusson, A., Savisaar, C., Bowsher, J.G., Burgett, M. and Donaldson, T.K. (2014) Risk of Impingement and Third-Body Abrasion with 28 mm Metal-on-Metal Bearings. Clinical Orthopaedics and Related Research, 472, 497-508. https://doi.org/10.1007/s11999-013-3399-3

[44] Leung, K., Ky, C., Ng, F. and Yin, L. (2013) Notching of the Femoral Stem Neck in Metal-on-Metal Total Hip Replacement: A Case Report. Journal of Orthopaedic Surgery, 21, 113-116. https://doi.org/10.1177/230949901302100129

[45] Onda, K., Nagoya, S., Kaya, M. and Yamashita, T. (2008) Cup-Neck Impingement Due to the Malposition of the Implant as a Possible Mechanism for Metallosis in Metal-on-Metal Total Hip Arthroplasty. Orthopedics, 31, 396. https://doi.org/10.3928/01477447-20080401-27

[46] Heiner, A.D., Lundberg, H.J., Baer, T.E., Pedersen, D.R., Callaghan, J.J. and Brown, T.D. (2008) Effects of Episodic Subluxation Events on Third Body Ingress and Embedment in the THA Bearing Surface. Journal of Biomechanics, 41, 2090-2096. https://doi.org/10.1016/j.jbiomech.2008.05.001

[47] Eberhardt, A.W., McKee, R.T., Cuckler, J.M., Peterson, D.W., Beck, P.R. and Lemon, J.E. (2009) Surface Roughness of CoCr and $\mathrm{ZrO}_{2}$ Femoral Heads with Metal Transfer: A Retrieval and Wear Simulator Study. International Journal of Biomaterials, 2009, Article ID: 185456.

[48] Lee, Y.K., Yoo, J.J., Koo, K.H., Yoon, K.S. and Kim, H.J. (2011) Metal Neck and Liner Impingement in Ceramic Bearing Total Hip Arthroplasty. Journal of Orthopaedic Research, 29, 218-222.

[49] Lundberg, H.J., Pedersen, D.R., Baer, T.E., Muste, M., Callaghan, J.J. and Brown, T.D. (2007) Effects of Implant Design Parameters on Fluid Convection, Potentiating Third-Body Debris Ingress into the Bearing Surface during THA Impingement/Subluxation. Journal of Biomechanics, 40, 1676-1685. https://doi.org/10.1016/j.jbiomech.2007.01.021

[50] Kligman, M., Furman, B.D., Padgett, D.E. and Wright, T.M. (2007) Impingement Contributes to Backside Wear and Screw-Metallic Shell Fretting in Modular Acetabular Cups. The Journal of Arthroplasty, 22, 258-264.

https://doi.org/10.1016/j.arth.2005.01.025

[51] Esposito, C.I., Walter, W.L., Roques, A., Tuke, M.A., Zicat, B.A., Walsh, W.R. and Walter, W.K. (2012) Wear in Alumina-on-Alumina Ceramic Bearings. A Retrieval Analysis of Edge Loading. The Journal of Bone and Joint Surgery, 7, 901-907. https://doi.org/10.1302/0301-620X.94B7.29115

[52] Shon, W.Y., Baldini, T., Peterson, M.G., Wright, T.M. and Salvati, E.A. (2005) Impingement in Total Hip Arthroplasty a Study of Retrieved Acetabular Components. The Journal of Arthroplasty, 20, 427-435. https://doi.org/10.1016/j.arth.2004.09.058

[53] Yamaguchi, M., Akisue, T., Bauer, T.W. and Hashimoto, Y. (2000) The Spatial Location of Impingement in Total Hip Arthroplasty. The Journal of Arthroplasty, 15, 305-313. https://doi.org/10.1016/S0883-5403(00)90601-6

[54] Clarke, I.C., Donaldson, T.K., Burgett, M.D., Smith, E.J., Bowsher, J., Savisaar, C., John, A., Lazennec, J.Y., McPherson, E. and Peters, C.L. (2013) Normal and Adverse Wear Patterns Created In-Vivo on MOM Surfaces-A Retrieval Study Representing Four Vendors. In: Kurtz, S.M., Greenwald, S.A., Mihalko, W.M. and Lemons, J.A., Eds., Metal-on-Metal Total Hip Replacement Devices, ASTM International, West Conshohocken, 157-192. https://doi.org/10.1520/STP156020120049

[55] Elsissy, J., John, A., Burgett, M., Clarke, I. and Donaldson, T. (2017) Biomechanical 
Impingement Evidence in Resurfacing Hip Cases Compared to Large Diameter MOM Total Hip Retrievals. ISTA Annual Congress, Seoul.

[56] Shishido, T., Clarke, I.C., Williams, P., Boehler, M., Asano, T., Shoji, H., Masaoka, T., Yamamoto, K. and Imakiire, A. (2003) Clinical and Simulator Wear Study of Alumina Ceramic THR to 17 Years and Beyond. Journal of Biomedical Materials Research, 67B, 638-647. https://doi.org/10.1002/jbm.b.10048

[57] Dorlot, J.M. (1992) Long-Term Effects of Alumina Components in Total Hip Prostheses. Clinical Orthopaedics and Related Research, No. 282, 47-52. https://doi.org/10.1097/00003086-199209000-00006

[58] Lundberg, H.J., Liu, S.S., Callaghan, J.J., Pedersen, D.R., O’Rourke, M.R., Goetz, D.D., Vittetoe, D.A., Clohisy, J.C. and Brown, T.D. (2007) Association of Third Body Embedment with Rim Damage in Retrieved Acetabular Liners. Clinical Orthopaedics and Related Research, 465, 133-139.

[59] Lewinnek, G.E., Lewis, J.L., Tarr, R., Compere, C.L. and Zimmerman, J.R. (1978) Dislocations after Total Hip-Replacement Arthroplasties. The Journal of Bone and Joint Surgery, 60, 217-220. https://doi.org/10.2106/00004623-197860020-00014

[60] Lazennec, J.Y., Rousseau, M.A., Brusson, A., Folinais, D., Amel, M., Clarke, I.C. and Pour, A.E. (2015) Total Hip Prostheses in Standing, Sitting and Squatting Positions: An Overview of Our 8 Years Practice Using the EOS Imaging Technology. The Open Orthopaedics Journal, 9, 26-44. https://doi.org/10.2174/1874325001509010026

[61] Kanawade, V., Dorr, L.D. and Wan, Z. (2014) Predictability of Acetabulare Component Angular Change with Postural Shift from Standing to Sitting Position. The Journal of Bone and Joint Surgery, 18, 978-986. https://doi.org/10.2106/JBJS.M.00765

[62] Phan, D., Bederman, S.S. and Schwarzkopf, R. (2015) The Influence of Sagittal Spinal Deformity on Anteversion of the Acetabular Component in Total Hip Arthroplasty. The Bone \& Joint Journal, 97-B, 1017-1023.

[63] Burgett, M.D., Donaldson, T.K. and Clarke, I.C. (2013) Denatured Protein Deposits Identical on Simulator and Explanted Hip Bearings. In: Kurtz, S.M., Greenwald, S.A., Mihalko, W.M. and Lemons, J.A., Eds., ASTM Symposium on Metal-on-Metal Total Hip Replacement Devices, ASTM International, West Conshohocken, 310-322. https://doi.org/10.1520/STP156020120047

[64] Clarke, I.C., Halim, T., Smith, E.J. and Donaldson, T. (2017) Acetabular Cups in 60 mm Metal-on-Metal Bearings Subjected to Dynamic Edge-Loading with 70 Degrees Peak Inclination in 10-Million Cycle Simulator Study. Lubricants, 6, 1.

[65] Burton, P., Medina, E., Burgett-Moreno, M., Donaldson, T.K. and Clarke, I.C. (2015) Biomechanical Alignment of Main Wear-Pattern on MOM Total Hip Replacement. Reconstructive Review, 5, 19-23. https://doi.org/10.15438/rr.5.2.111

[66] Bowsher, J.G., Donaldson, T.K., Williams, P.A. and Clarke, I.C. (2008) Surface Damage after Multiple Dislocations of a 38-Mm-Diameter, Metal-on-Metal Hip Prosthesis. The Journal of Arthroplasty, 23, 1090-1096.

https://doi.org/10.1016/j.arth.2007.09.007

[67] Malik, A., Dorr, L.D. and Long, W.T. (2009) Impingement as a Mechanism of Dissociation of a Metasul Metal-on-Metal Liner. The Journal of Arthroplasty, 24, 313-326. https://doi.org/10.1016/j.arth.2008.05.023

[68] Marchetti, E., Krantz, N., Berton, C., Bocquet, D., Fouilleron, N., Migaud, H. and Girard, J. (2011) Component Impingement in Total Hip Arthroplasty: Frequency and Risk Factors. A Continuous Retrieval Analysis Series of 416 Cup. Orthopaedics 
\& Traumatology: Surgery \& Research, 97, 127-133.

https://doi.org/10.1016/j.otsr.2010.12.004

[69] McMurtrie, A., Abhijit, R., Guha, A.R. and Wootton, J.R. (2009) Loose Metasul Liner Causing Partial Amputation of the Neck of the Femoral Component. Journal of Arthroplasty, 24, 151-153. https://doi.org/10.1016/j.arth.2008.01.314

[70] McPherson, E.J., Clarke, I.C., Donaldson, T.K. and Burgett, M.D. (2013) A MOM Dislocator Case Demonstrating Importance of Impingement Damage in Triggering Adverse 3rd-Body Abrasive Wear Risks. Orthopedics Today, Hawaii, 13-16 January 2013.

[71] Donaldson, T.K., Burgett-Moreno, M. and Clarke, I.C. (2015) Excessive Anteversion Leads to Failure at 3 Years Due to Impingement as Evidenced by Twin Notches in Ti6A4V Stem. Reconstructive Review, 5, 25-28. https://doi.org/10.15438/rr.5.2.110

[72] McPherson, E. and Peters, C. (2010) Correction of Femoral Acetabular Impingement at the Time of Primary Large Diameter Metal-Metal THA. Scientific Poster, AAOS, New Orleans.

[73] Pelt, C.E., Erickson, J., Clarke, I.C., Donaldson, T.K., Layfield, L. and Peters, C.L. (2013) Histologic, Serologic, and Tribologic Findings in Failed Metal on Metal Total Hip Arthroplasty. AAOS Exhibit Selection. The Journal of Bone and Joint Surgery, 95, e163. https://doi.org/10.2106/JBJS.L.01446

[74] McHugh, D., Currier, J., Kennedy, F., Collier, J. and Van Critters, D. (2013) Plastic Deformation from Edge Loading Is Common on Retrieved Metal-on-Metal Hips and Can Be Predicted with Finite Element Analysis. In: Kurtz, S.M., Greenwald, S.A., Mihalko, W.M. and Lemons, J.A., Eds., Metal-on-Metal Total Hip Replacement Devices, 235-250.

[75] Bengs, B.C., Sangiorgio, S.N. and Ebramzadeh, E. (2008) Less Range of Motion with Resurfacing Arthroplasty than with Total Hip Arthroplasty. Acta Orthopaedica, 79, 755-762. https://doi.org/10.1080/17453670810016812

[76] McKellop, H., Hart, A., Hothi, H. and Campbell, P. (2014) A Lexicon for Wear of Metal-on-Metal Hip Prostheses. Journal of Orthopaedic Research, 32, 1221-1233. https://doi.org/10.1002/jor.22651

[77] Lazennec, J.Y., Boyer, P., Poupon, J., Rousseau, M.A., Roy, C., Ravaud, P. and Catonne, Y. (2009) Outcome and Serum Ion Determination up to 11 Years after Implantation of a Cemented Metal-on-Metal Hip Prosthesis. Acta Orthopaedica, 80, 168-173. https://doi.org/10.3109/17453670902947408

[78] Walker, P.S. and Gold, B.L. (1971) The Tribology (Friction, Lubrication and Wear) of All-Metal Artificial Hip Joints. Wear, 17, 285-299. https://doi.org/10.1016/0043-1648(71)90032-9

[79] Lundberg, H.J., Stewart, K.J., Callaghan, J.J. and Brown, T.D. (2005) Kinetically Critical Sites of Femoral Head Roughening for Wear Rate Acceleration in Total Hip Arthroplasty. Clinical Orthopaedics and Related Research, 430, 89-93. https://doi.org/10.1097/01.blo.0000150450.42829.b8

[80] Band, T.J., Ashton, R.W.F. and Kamali, A. (2009) Retrieval Analysis. In: McMinn, D., Ed., Modern Hip Resurfacing, Springer, Berlin, 93-112. https://doi.org/10.1007/978-1-84800-088-9_6

[81] Vendittoli, P.A., Roy, A., Mottard, S., Girard, J., Lusignan, D. and Lavigne, M. (2010) Metal Ion Release from Bearing Wear and Corrosion with $28 \mathrm{~mm}$ and Large-Diameter Metal-on-Metal Bearing Articulations. The Journal of Bone \& Joint 
Surgery, 92B, 12-19. https://doi.org/10.1302/0301-620X.92B1.22226

[82] Halim, T., Burgett, M., Donaldson, T. and Clarke, I. (2015) Third-Body Wear Damage Produced in CoCr Surfaces by Hydroxyapatite and Alumina Ceramic Debris: A 10-Cycle Metal-on-Metal Simulator Study. Reconstructive Review, 5, 33-39. https://doi.org/10.15438/rr.5.4.129

[83] Halim, T., Clarke, I.C., Burgett-Moreno, M., Donaldson, T.K., Savisaar, C. and Bowsher, J.G. (2015) A Simulator Study of Adverse Wear with Metal and Cement Debris Contamination in Metal-on-Metal (MOM) Hip Bearings. Bone \& Joint Research, 4, 29-37. https://doi.org/10.1302/2046-3758.43.2000332

[84] Lundberg, H.J., Stewart, K.J., Pedersen, D.R., Callaghan, J.J. and Brown, T.D. (2006) Problematic Sites of Third Body Embedment in Polyethylene for Total Hip Wear Acceleration. Journal of Biomechanics, 39, 1208-1216. https://doi.org/10.1016/j.jbiomech.2005.03.014

[85] Clarke, I.C., Burgett, E.J., Donaldson, T.K., McPherson, E., Peters, C.L., Lazennec, J.Y., Savisaar, C. and Bowsher, J.G. (2013) Macro-Damage Abrasion Mode Created by Particulates Formed during Impingement of Large-Diameter MOM Bearings. Orthopedic Research Society, San Antonio, 1788.

[86] Doorn, P.F., Campbell, P.A., Worrall, J., Benya, P.D., McKellop, H.A. and Amstutz, H.C. (1998) Metal Wear Particle Characterization from Metal on Metal Total Hip Replacements: Transmission Electron Microscopy Study of Periprosthetic Tissues and Isolated Particles. Journal of Biomedical Materials Research, 42, 103-111. https://doi.org/10.1002/(SICI)1097-4636(199810)42:1<103::AID-JBM13>3.0.CO;2$\underline{\mathrm{M}}$

[87] Park, S.H., McKellop, H., Lu, B., Chan, F.W. and Chiesa, R. (1998) Wear Morphology of Metal-Metal Implants: Hip Simulator Tests Compared with Clinical Retrievals. In: Jacobs, J. and Craig, T.L., Eds., Alternative Bearing Surfaces in Total Joint Replacement, ASTM, Fredericksburg, 129-143. https://doi.org/10.1520/STP12835S

[88] Goldsmith, A.A., Dowson, D., Isaac, G.H. and Lancaster, J.G. (2000) A Comparative Joint Simulator Study of the Wear of Metal-on-Metal and Alternative Material Combinations in Hip Replacements. Proceedings of the Institution of Mechanical Engineers, 214, 39-47. https://doi.org/10.1243/0954411001535228

[89] Riviere, C., Lazennec, J.Y., Van Der Straeten, C., Auvinet, E., Cobb, J. and Muirhead-Allwood, S. (2017) The Influence of Spine-Hip Relations on Total Hip Replacement: A Systematic Review. Orthopaedics \& Traumatology: Surgery \& Research, 103, 559-568. https://doi.org/10.1016/j.otsr.2017.02.014

[90] Oparaugo, P.C., Clarke, I.C., Malchau, H. and Herberts, P. (2001) Correlation of Wear Debris-Induced Osteolysis and Revision with Volumetric Wear-Rates of Polyethylene: A Survey of 8 Reports in the Literature. Acta Orthopaedica Scandinavica, 72, 22-28. https://doi.org/10.1080/000164701753606644 


\section{Listing of Abbreviations}

2CR: 2-body wear on head (by cup rim)

3CR: $3^{\text {rd }}$-body wear on head (entrapped metal particles)

2OR: 2-body defects created during surgery (instruments, head dislocation)

3CO: $3^{\text {rd }}$-body wear by CoCr particle

3TI: $3^{\text {rd }}$-body wear by Ti6Al4V particle

COC: ceramic-on-ceramic hip bearing

CoCr: cobalt chromium alloy

ECD: algorithm utilizing equivalent circle diameter

EDS: Energy dispersive spectroscopy

EOS: EOS $^{\circledast}$ system for low-dose 3D imaging of patients

FHG: femoral-head gouges (plastic deformation)

MOM: metal-on-metal hip bearing

MPE: metal-on-polyethylene hip bearing

MWZ: main-wear zone (area of normal, habitual wear)

NAR: femoral-neck abrasion by cup rim

NWZ: non-wear zone (area of infrequent or non-wear)

RA: resurfacing arthroplasty

SEM: scanning electron microscopy

THA: total hip arthroplasty

Ti6Al4V: titanium alloy

TTL: Titanium transfer layer

WLI: white-light interferometry 